\title{
FREQUENCY OF VIOLATION AND CONSTRAINT-BASED PHONOLOGICAL LEARNING*
}

\author{
Anne-Michelle Tessier \\ University of Alberta
}

\begin{abstract}
This paper provides two arguments that constraint-based grammars should not be learned by directly mirroring the frequency of constraint violation and satisfaction in the target words of a language. The first argument comes from a class of stages attested in phonological development, called Intermediate Faith (IF) stages, in which children produce marked structures only in privileged positions. Two such stages are presented and analyzed, from the literature on English and French L1 acquisition, and their learning consequences are examined. The second argument concerns the degree of restrictiveness that a learner's end-state grammar encodes, using two hypothetical interactions between learner's assumptions about hidden structure and developing constraint rankings that can trick a learner into adopting a superset grammar. These two arguments are used to support an approach called Error-Selective Learning (ESL), in which errors are learned and stored gradually, in a way that relies on violation frequency, but rankings themselves are learned in a non-gradual way (relying on the algorithms of Prince and Tesar 2004; Hayes 2004). It is also shown that violation frequencies can still cause problems regardless of a learner's method of grammatical evaluation - either ranked constraints as in Optimality Theory, or weighted constraints as in Harmonic Grammar.
\end{abstract}

\section{INTRODUCTION}

Current theories of learning in constraint-based theories like Optimality Theory (Prince and Smolensky 1993/2004), and a substantial body of work on L1 and L2 phonological development, are beginning to allow researcher to assess the match between learnability theories and empirical predictions. The recent literature has seen a large body of work whose main goal is to characterize, using OT tools, the pre-target production grammars of L1 learners (beginning with e.g. Demuth and Fee 1995, Gnanadesikan 1995/2004, Demuth 1996, Pater 1997.) At the same time, OT learnability work has sought to answer a different but related question: how to build a learner that uses the available errors to reach the right target final grammar (see references throughout this paper.) In nearly all of this latter work, the learner is assumed to be error-driven, meaning that it proceeds from each stage to the next by making errors, comparing its errors to the target forms, and changing its grammar in some way as a result.

This paper is part of a research program that seeks to integrate results from both domains, by asking to what extent learners that are successful from a learnability perspective are also good at replicating the human learning process. How do real learners get from one time-slice grammar to the next? Some learnability work is very careful to not make claims about how humans learn, and fairly so - but Optimality Theory (and other constraint-based grammars) are proposed, in the

\footnotetext{
* Thanks to Michael Becker, Karen Jesney, Marnie Krauss, John McCarthy, Marcin Morzycki, Mits Ota, Johanne Paradis, Joe Pater, Tamara Sorenson Duncan, Shelley Velleman and participants at BUCLD30 and WCCFL25, as well as Hildibrandt Barca and Tracy O'Brien. Special thanks to two anonymous reviewers for important challenges and alternatives that have greatly improved this material. As always, none of the above are responsible for any of my errors.
} 
generative tradition, as a way of capturing what humans know about their native language phonology, and learnability insights about constraint-based grammars are also insights into the properties of a system that human learners must somehow come to know.

The particular issue that this paper addresses is what makes a constraint-based learner gradual: that is, what mechanism in the learning process ensures that learners move incrementally from the initial to final states, and how the stages in between are determined. I will consider two potential answers. The first, which might be viewed as the default assumption, is that learners are gradual because they re-rank their constraints in a gradual fashion. In this approach, constraints must be given numerical values of some kind; on the basis of each error made by the learner, these values are slowly brought closer together or farther apart and over time approximate the end-state grammar. This approach is fairly simple, frequently successful, and appealing in its straightforward account of various aspects of learning, notably variation - however, I will argue against it. Instead, I will suggest that the gradualness of grammar learning should come from the gradual incorporation of errors into the learner's system, and that the method of re-ranking on the basis of any particular set of errors should not be incremental but rather complete (in a way that will become precise.) The core argument here will be that - regardless of which kind of grammar is chosen - gradual learning should not be derived from gradual re-ranking.

Two tests of gradual learners are considered in this paper: the intermediate stages the learner passes through, and the end-state grammars that it eventually chooses. The first comes from a particular class of attested developmental stages, one in which children are preferentially faithful to material in the privileged positions of target words (which will be assumed here to be synonymous with inputs.) In this paper I will use the term 'Intermediate Faith' (IF) as a cover term for this class of stages, and analyze them with crucial reference to positional faithfulness constraints. Under the standard assumption that initial-state phonological grammars allow little markedness in outputs and eventually come to allow all the marked structures on the target (Smolensky 1996 et seq), the position of an IF stage along the learning trajectory is shown schematically below:

(1) Three stages of constraint re-ranking in development

$\begin{array}{lll}\text { a. } & \text { initial state: } & * \mathbf{X}>>\text { Faith-X(PrivilegedPosition), Faith-X } \\ \text { b. } & \text { intermediate } & \text { Faith-X(PrivilegedPosition) }>>* \mathbf{X}>>\text { Faith-X } \\ \text { c. } & \text { target } & \text { Faith-X(PrivilegedPosition), Faith-X }>>* \mathbf{X}\end{array}$

The literature contains many examples of children whose phonologies contain IF stages; section 2 will present two examples from this perspective.

The learnability question is what kind of constraint-based learner can be induced to pass through an IF stage like 1b) on its way from 1a) to 1c). The reason this particular stage is a challenge for a gradual learner that re-ranks gradually, using each error to affect a slight reranking, is that such stages cannot be reproduced by an OT learner directly from the frequency of constraint violations. This claim will be spelled out more in section 3 , but the basic idea is as follows. Suppose the learner is being exposed to a language that tolerates complex onsets and has 
word-final stress. In the initial state, the high-ranking markedness constraint *COMPLEX will ensure that complex onsets will be simplified at the expense of faithfulness. If we suppose that our learner's constraint set includes two faithfulness constraints against deletion - general MAX and more specific MAX/STRESSEDSYLLABLE - then the learner will be making errors with violation profiles shown below:

(2) Two kinds of complex onset errors at the initial state:

$\begin{array}{llll} & \begin{array}{l}\text { Target } \\ \text { output }\end{array} & \begin{array}{l}\text { Learner's } \\ \text { output }\end{array} & \begin{array}{l}\text { Constraints violated } \\ \text { by the error: }\end{array} \\ \begin{array}{ll}\text { a. deletion in stressed } \sigma: & \mathrm{CV} . ' \mathrm{CCV}\end{array} & \mathrm{CV} .{ }^{\prime} \underline{\mathrm{CV}} & \text { MAX, MAX/STRESSED } \\ \text { b. deletion in unstressed } \sigma: & \mathrm{CCV} .{ }^{\prime} \mathrm{CV} & \underline{\mathrm{CV}} .{ }^{\prime} \mathrm{CV} & \text { MAX }\end{array}$

What the final column of this table shows is that a more general faithfulness constraint is violated more frequently than a specific one. This means that if frequency directly drives the rate at which rankings are revised by the gradual learner, the general MAX constraint's importance in the ranking will be increased faster than that of the specific MAX/STRESSED. Thus, a purely frequency-driven gradual learner will not reach an IF stage where complex onsets are protected only in stressed syllables, under the influence of MAX/STRESSED. Nevertheless, section 2.1 points to a stage of French acquisition in which just this pattern is attested.

The direct correlation between frequency of violation and gradual re-ranking, shown to cause problems in the example above, is perhaps best known from the Gradual Learning Algorithm (GLA: Boersma, 1997; Boersma and Hayes 2001 ${ }^{1}$ ) - though of course many authors have used more nuanced versions of a GLA learner. ${ }^{2}$ Section 3 presents the core of the GLA, the stochastic OT grammars it learns and its problem with IF stages, setting the stage for the rest of the paper's investigation.

In section 4, I provide my own proposal of an alternative method of gradual learning. The key idea to begin with a very efficient, non-gradual OT learning algorithm - one that knows nothing of violation frequencies - and then to gradually feed it errors that will each push it to the next developmental stage. This approach is called Error-Selective Learning (ESL: Tessier 2006, 2007), and its constraint re-ranking algorithm is a version of Biased Constraint Demotion (Prince and Tesar 2004), which also incorporates aspects of the Low Faithfulness Constraint Demotion (Hayes 2004.) Section 4 demonstrates how ESL will produce IF stages if the right errors are available to the learner, illustrating with the French example already schematized above.

Section 5 presents a recent alternative, quite different approach to IF stages: one in which a method very similar to the GLA is retained as the method of gradual learning, but where the method of evaluation is changed: replacing OT's constraint ranking with constraint weighting, as in Harmonic Grammar (Legendre et al 1990ab; Legendre et al 2006; Pater, to appear; Potts,

\footnotetext{
${ }^{1}$ See also Appousidou 2007, Boersma and Appousidou 2004, Boersma and Levelt 2000; Boersma and Hayes 2001, Curtin and Zuraw, 2001, Levelt and van der Vijver 2004.

${ }^{2}$ Including but certainly not limited to Hayes and Londe 2006, and Zuraw 2000. See also section 6.
} 
Pater, Bhatt and Becker 2008; Pater, Bhatt and Potts 2007; see also Prince 2002a.) ${ }^{3}$ Following Jesney and Tessier $(2007,2008)$, section 5 shows how an incremental, GLA-like learner of a weighted constraint grammar ${ }^{4}$ will pass through the Intermediate Faith stage in $1 \mathrm{~b}$ ), purely as a result of the way its evaluation metric chooses optimal forms. The Harmonic Grammar approach is presented here because it demonstrates the need for further evidence to distinguish between the gradual re-ranking and gradual error-accumulation approaches.

With these two possible approaches to IF stages in mind, the paper then turns to the second testing ground: a gradual learner's ability to converge on the correct end-state grammar. Here I argue that despite the success of the GLA-like learner at producing IF stages in a Harmonic Grammar, it still has drawbacks as a model of gradual human phonological development, and that these stem from its reliance on frequency of violation and incremental re-ranking. Section 6 presents a case in point, which I will refer to as the 'winner misparse' problem. The crucial initial observation is that before any learner can correctly use its errors and their violation frequencies to learn, it must have made the correct representational assumptions about the hidden structure of those errors - syllable boundaries, foot groupings, morphological structure, and so forth (e.g. Tesar 1998; see also Dresher 1999.) Should the learner make the wrong assumptions temporarily, the learner may fall into a so-called 'superset language' (Berwick 1985 et seq), from which the learner must recover in order to reach the correct end-state grammar.

As is spelled out in section 6, the relevance of this superset trap is that recovery to a more restrictive final grammar is unproblematic for the Error-Selective learner, falling out rather directly from the mechanisms by which gradual development is achieved, but is much more problematic for a gradual re-ranker like the GLA. I present two hypothetical examples to make this argument, emphasizing that this issue arises through the interactions of both faithfulness and markedness constraints, and using either ranked or weighted constraints. The discussion of these 'winner misparse' traps also emphasizes the need to use stored errors in gradual learning, rather than a purely online learner that remembers only one error at a time.

Section 7 concludes the paper, including a summary of the various constraint-based learners presented, and also discusses how the type of grammar adopted (constraint ranks vs. weights) and the type of learning algorithm adopted each contribute to a theory's success in learning restrictively and yet gradually.

\footnotetext{
${ }^{3}$ There are currently a number of independent approaches to learning phonologies with weighted constraints, such as Maximum Entropy (Goldwater and Johnson 2003; Jaeger 2007), as well as OT grammars which themselves are weighted, using Maximum Likelihood estimation (Jarosz 2006). None of these will be explored in any detail in this paper, though their ultimate connection to the issues raised here is an important topic for future research; however, see the arguments of section 7.2, which apply in principle to any grammar of weighted constraints. For some related but different comparative results, see Jesney (2007).

${ }^{4}$ Note that this learner is very similar to the GLA, but not strictly speaking quite the same as the GLA: on the difference and the connection to the perceptron update rule of Rosenblatt (1956), see Jaeger (2007), Pater (2007), Jesney and Tessier (2007). In an attempt to minimize a potentially infuriating terminological confusion on this point, I will always use the term 'GLA-like algorithm' when discussing the learning of Harmonic Grammars in section 5, but readers not invested in the details may pretend this to be the familiar GLA algorithm without losing any of the plot.
} 


\section{INTERMEDIATE FAITH STAGES IN NATURAL PHONOLOGICAL ACQUISITION}

This section provides two representative examples of intermediate faith stages, one from a crosssectional experiment of English prosodic development (Kehoe and Stoel-Gammon 1997, Kehoe 2000) and one from a diary study of the phonological acquisition of Québécois French (Rose 2000). Since the major focus of this paper are the learning consequences of IF stages, an exhaustive list of the phenomena is not provided; for more such stages see Tessier (2007), as well as Jesney and Tessier (2007, to appear); Revithiadou and Tzakosta (2004).

It should be noted that this paper does not argue that positional faith constraints are the only way that a phonology can encode contextually-restricted patterns; such patterns can often be treated as the effects of either a specific faithfulness or a specific markedness constraint (see e.g. Beckman 1998: 153-184 for a pattern that only specific faithfulness can capture; but cf Zoll 1998.) In other cases, it might perhaps be the case that two different specific faithfulness constraints with complementary contexts could produce the same restrictions; this possibility will be discussed in the text below. For present purposes, the sufficient claim is that some positional faithfulness constraints are necessary to capture the range of both developing and adult grammars, and therefore that their learning consequences must be taken seriously.

\subsection{Intermediate Faith in French Stressed Syllables}

The first Intermediate Faith stage, already introduced in section 1, comes from Rose (2000) who documents stages in the acquisition of Québécois French by two children, Clara and Théo. He presents evidence of a stage at which complex onsets are preserved faithfully in stressed syllables, but the same clusters are reduced to singleton in unstressed syllables (see Rose 2000: 130-133):

(3) The initial stage

$$
\text { /...CCVC.../ } \rightarrow[\ldots \mathrm{CVC} \ldots]
$$

The French intermediate stage

$/ \mathrm{CV} .{ }^{\prime} \mathrm{CCV} / \rightarrow \quad$ [CV.'CCV], *[CV.'CV]

$/ \mathrm{CCV} .{ }^{\prime} \mathrm{CV} / \rightarrow\left[\mathrm{CV} .{ }^{\prime} \mathrm{CV}\right], *\left[\mathrm{CCV} .{ }^{\prime} \mathrm{CV}\right]$

(4) Théo's onset cluster acquisition ${ }^{5}$

a. All onset clusters simplified (up to 2;05.11)

\begin{tabular}{|c|c|c|c|c|c|}
\hline \multicolumn{3}{|c|}{ stressed syllables } & \multicolumn{3}{|c|}{ unstressed syllables } \\
\hline Target & Child & Gloss & Target & Child & Gloss \\
\hline /klun/ & [kun] & 'clown' & /bri'ze/ & [pi'že:] & 'broken' \\
\hline$/ \mathrm{t} x \tilde{\varepsilon}$ & [kع] & 'train' & & & \\
\hline
\end{tabular}

\footnotetext{
${ }^{5}$ See Rose (2000) §3.4.1 for the full details of Théo's stop-liquid acquisition.
} 
b. Intermediate stage: complex onsets in stressed syllables only $(2 ; 05.29-2 ; 11.29)$

\begin{tabular}{|c|c|c|c|c|c|}
\hline \multicolumn{3}{|c|}{ stressed syllables: retained } & \multicolumn{3}{|c|}{ unstressed syllables: reduced } \\
\hline /go/ & [gвo] & 'big' & /txak.tœь / & [ta.'tæev] & tractor \\
\hline$/ \mathrm{tx} \tilde{\varepsilon}$ & {$[\mathrm{k} \times \varepsilon]$} & 'train' & /gву.jo/ & [ $\left.k^{h} œ . ' j \jmath\right]$ & oatmeal \\
\hline / kle/ & {$[\mathrm{kxi}]$} & 'key' & /txu.ve/ & [kv.'Bi] & found \\
\hline / plœь / & [plœv] & '(he/she)cries' & /,kxعm.gla.se/ & {$\left[{ }_{1} k x a^{\mathrm{I}} \cdot\right.$ na.'se] } & ice cream \\
\hline
\end{tabular}

c. All onset clusters retained (3;0.7 onwards)

\begin{tabular}{|c|c|c|c|c|c|}
\hline \multicolumn{3}{|c|}{ stressed syllable } & \multicolumn{3}{|c|}{ unstressed syllable } \\
\hline Target & Child & Gloss & Target & Child & Gloss \\
\hline \multirow{4}{*}{\multicolumn{3}{|c|}{ (none cited) }} & /txu.ve/ & [kxa.ə've] & 'found' \\
\hline & & & /pxə.ne/ & [рьә.'ne] & '(you.pl) take' \\
\hline & & & /plœ.ве/ & [plø.'ве] & 'to cry' \\
\hline & & & /gli.sad/ & [kli.'sad] & 'slide' \\
\hline
\end{tabular}

The structural constraint responsible for the general reduction of clusters across stages can be defined simply as in (5):

(5) *COMPLEX:

No tautosyllabic consonant clusters

Following a number of previous studies, I will assume that the constraint responsible for (4b)'s faithfulness in stressed syllables is a positional faithfulness constraints as in (6a) below. This constraint protects segments in the perceptually salient context of input stress, defined here over the syllable. (For discussion of such constraints in various analyses see e.g. Beckman 1998; Smith 2001, as well as Curtin 2002's MAX-PiтchProm; cf. Steriade 1999) I also adopt the usual MAX constraint in (6b) relevant to all segments, regardless of stressed quality:

(6) a) MAX-IO/STRESSEDSYLLABLE ${ }^{6}$ :

An Input segment in a stressed syllable must have an Output correspondent

b) MAX-IO:

An Input segment must have an Output correspondent

\footnotetext{
${ }^{6}$ This definition assumes that inputs are syllabified, at least for children/learners. For the purposes of this paper I will make this assumption without justification, although ultimately one must be found. For some summary of the known issues see Tessier (2007: 102-104); I take these definitional concerns to be an important and unresolved issue. In this case, the constraint Max-PitchProm might be defined carefully so as to include all and only the onset segments adjacent to a stressed vowel, but the details of such an account will be left aside here,

An alternative analysis is to assume two markedness constraints, *COMPLEX/UNSTRESSEDSYLLABLE and *COMPLEX, and a single MAX constraint. As alluded to at the top of this section, I do not argue explicitly against such an alternative in this paper; I only refer to the body of work showing that some positional faithfulness constraints must exist. In that light, the learner will inevitably be faced with constraint pairs similar to those in (6ab), and thus will need to manage their consequences.
} 
The ranking that accounts for the Intermediate Faith stage is one that sandwiches *COMPLEX between the two faithfulness constraints, as in (7). This grammar produces the right results, as illustrated in (8):

(7) The French IF stage: MAX/STRESSED $>>*$ COMPLEX $>>$ MAX $^{7}$

(8) Effects of the French IF stage

a. MAX/STRESSED $>>*$ COMPLEX protects clusters in stressed syllables

\begin{tabular}{|c||c|c|}
\hline$/ \mathrm{gl}$ Is $/$ & MAX/STRESSED & $*$ COMPLEX \\
\hline \hline klIs & & $*$ \\
\hline kIs & $* !$ & \\
\hline
\end{tabular}

b. *COMPLEX $>>$ MAX reduces clusters elsewhere

\begin{tabular}{|c||c|c|c|}
\hline$/$ glı.sad & MAX/ STRESSED & *COMPLEX & MAX \\
\hline \hline kla.'sad & & $* !$ & \\
\hline ka.'sad & & & $*$ \\
\hline
\end{tabular}

Some similar French data comes from Kehoe and Debove-Hilaire (2003), with respect to the acquisition of consonant-glide rather than stop-liquid sequences (though see that work for the author's interpretation of their results.) The 14 children in their experiment (ages 1;10 -2;9, mean age $2 ; 4)$ preserved both members of two consonant-glide clusters (consonant-[w] and consonant[l] ) more often in stressed than unstressed syllables $(\mathrm{p}<0.01)$. For two children, the effect was fairly categorical, in that consonant-glide sequences were retained $100 \%$ of the time in stressed syllables, but less than $20 \%$ of the time in unstressed syllables.

\subsection{Intermediate Faith to English Stressed Syllables}

A different kind of IF stage is found in the extensive literature on syllable truncation, where it is often found that children resist the pressure to delete entire syllables from a privileged position (see e.g. Echols and Newport 1992; Fikkert 1994; Gerken 1996; Pater 1997.) With respect to the stressed syllable position, Kehoe and Stoel-Gammon (1997) and Kehoe (2000) report on an elicitation study of English-speaking children at 2;4 and 2;10, designed in part to test for stress effects on syllable truncation. In their data, truncation patterns were almost exclusively restricted to unstressed syllables while stressed ones were retained.

A good example of stressed syllable preservation that suggests a role for MAX/STRESSED comes from one child in this study, $27 \mathrm{~m} 6$. From the present perspective, this child's truncation patterns fall into two categories. In word with one input stress, outputs are truncated to a single trochaic foot (data all taken from Kehoe 2000: table 6.)

\footnotetext{
${ }^{7}$ For evidence of this pattern in adult language, see Goad and Rose (2004) on Brazilian Portugese.
} 
27m6's productions of target words with one stress

\begin{tabular}{|l|l|l|}
\hline Schema: & Examples & \\
\hline$/ \mathrm{w} \mathbf{S} / \rightarrow(\mathrm{S})$ & 'giraffe' & [dwaef] \\
\hline$/ \mathrm{wS} \mathrm{W} / \rightarrow(\mathrm{Sw})$ & 'banana' & {$[$ 'bani] } \\
\hline & 'tomato' & ['medo] \\
\hline$/ \mathrm{Sww} / \rightarrow(\mathrm{Sw})$ & 'elephant' & ['ElIf] \\
\hline
\end{tabular}

The examples in (9) show that at this stage, $27 \mathrm{~m} 6$ always retains the target stressed vowel; the onset that surfaces in the output stressed syllable may also be the target stressed syllable vowel (as in 'tomato') or another input consonant (as in 'banana' and possibly 'giraffe'.) The grammar's choice of unstressed target onsets in these latter cases can be attributed to markedness constraints that independently prefer low-sonority onsets (see more on this later in the section.)

For words with two input stresses, both stresses must be retained in some form. This can be seen in $27 \mathrm{~m} 6$ 's spontaneous productions of three and four syllable words below:

\begin{tabular}{|c|c|c|}
\hline Schema: & \multicolumn{2}{|l|}{ Examples } \\
\hline$/ \mathrm{SS} / \quad \rightarrow(\mathrm{S})(\mathrm{S})$ & 'raccoon' & [ıæ'kun] \\
\hline$/ \mathrm{SwS} / \quad \rightarrow(\mathrm{Sw})(\mathrm{S})$ & 'kangaroo' & [,kænno'ja] \\
\hline$/ \mathrm{SwSw} / \rightarrow(\mathrm{Sw})(\mathrm{S})$ & 'alligator' & ['æbi,gعג] \\
\hline$(\mathrm{S})(\mathrm{Sw})$ & 'helicopter' & ['ha,kapr] \\
\hline$(\mathrm{S})(\mathrm{Sw})$ & 'avocado' & [, $a^{\prime}$ kado] \\
\hline
\end{tabular}

To explain the one-foot pattern of truncation in 9), we can use Markedness constraints that require a foot to be aligned with both the left and right edges of the word. This one-foot stage in phonological development has often been derived using gradient Align ( $\mathrm{Ft}, \mathrm{PWd}$ ) constraints (e.g. Pater 1997), but in light of McCarthy (2003)'s influential arguments against such gradient constraints an alternative analysis is called for. ${ }^{9}$ In fact, McCarthy (2003) re-interprets single foot (i.e. non-iterative) stress systems in adult grammars as the result of END-RULE constraints (following Prince 1983). These require the head foot in a Prosodic Word to be either the first or the last:

11) End-Rule-Left/Right (Prince 1983, McCarthy 2003: p.111)

The head foot is not preceded/followed by another foot within the Prosodic Word

If both of these constraints are ranked high, along with the constraint PARSE- $\sigma$ which requires all syllables to be footed, all outputs will be truncated to a single foot. This ranking, given in (12), results in truncation of unstressed syllables that do not form part of the head foot, both at the beginning and ends of words, illustrated in (13):

\footnotetext{
${ }^{8}$ One additional /SwS/ word, 'dinosaur', fluctuated in imitations between SS and SwS productions.

${ }^{9}$ Thanks to an anonymous reviewer for pushing me to pursue different analyses of this stage.
} 
12) Truncation to a single foot as in (9): PARSE- $\sigma$, END-RULE L/R $>>$ MAX

13)a) $/ \mathrm{wSw} /$ truncated to $(\mathrm{Sw})$ :

\begin{tabular}{|c|c|c|c|}
\hline /'عlıfənt/ & PARSE- $\sigma$ & END-RULE-R & MAX \\
\hline ('عlI)fənt & $* !$ & & \\
\hline ('عlI)( fənt & & $* !$ & \\
\hline 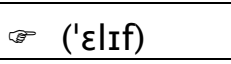 & & & $* * *$ \\
\hline
\end{tabular}

13b) /Sww/ truncated to $(\mathrm{Sw})$

\begin{tabular}{|c|c|c|c|}
\hline /bə'næn^/ & PARSE- $\sigma$ & END-RULE-L & MAX \\
\hline bə('nani) & $* !$ & & \\
\hline (bə)('nani) & & $* !$ & \\
\hline ('bani) & & & $* * *$ \\
\hline
\end{tabular}

Despite this general pattern, the longer words in (10) show that END-RULE L/R are in fact violable in this grammar - just in cases where truncating to a single foot would require deletion of a stressed syllable. This means that the same MAX/STRESSED constraint from the analysis of French is also crucial here: ranked above the END-RULE constraints, it derives the right results as in 14.

14) Preservation of two feet in (15): MAX/STRESSED $>>$ END-RULE L/R

15) a) /SwS/ preserved faithfully:

\begin{tabular}{|c|c|c|}
\hline /,kæクgә'גu/ & MAX/STRESSED & END-RULE-L \\
\hline ('ja) & $* * * !$ & \\
\hline ('kæyno) & $* * !$ & \\
\hline$($ (kænno)('ja) & & * \\
\hline
\end{tabular}


15)b) $/ \mathrm{SwSw} /$ targets retain two feet: ${ }^{10}$

i) primary stress on the initial foot: helicopter

\begin{tabular}{|c||c|c|}
\hline$/$ 'helI,kapta/ & MAX/STRESSED & END-RULE-R \\
\hline \hline ('kape) & $* * !$ & \\
\hline$*$ ('ha)(,kape) & & $*$ \\
\hline
\end{tabular}

ii) primary stress on the final foot: avocado

\begin{tabular}{|c||c|c|}
\hline /,avə'kado/ & MAX/STRESSED & END-RULE-L \\
\hline ('kado) & $* !$ & \\
\hline$($ ( a)('kado) & & $*$ \\
\hline
\end{tabular}

The grammar of $27 \mathrm{~m} 6$ is thus another IF stage - one in which multiple feet are allowed, in violation of END-RULE, only when input stressed syllables are at stake.

16) Full ranking for English IF stage

PARSE- $\sigma$, MAX/STRESSED $>$ END-RULE-L, R > MAX

A reviewer raises an alternative explanation for the truncation of unstressed syllables in developing grammars: that children have not encoded these unstressed syllables into their underlying representations, due in one way or another to their lesser salience. The evidence that input deficits cannot be the whole story comes from examples like banana, produced as ['bani] in 13b). While $27 \mathrm{~m} 6$ does not retain the entire unstressed syllable, his grammar nevertheless retains the unstressed syllable's onset segment, [b], reflecting the common tendency for developing grammars to select low-sonority onset segments. A more dramatic example of this comes from Gnanadesikan (1995/2004), who reports a child whose initial pretonic syllables were all over-written with a fixed segmental template [fi] (e.g. [fi.be.ya] for umbrella) but for whom the segmental content of the stressed syllable was similarly affected by the sonority of the unstressed syllable she had over-written. As in ['bani], this child's grammar chose stop onsets over liquids, resulting in forms such as [fi.pis] for police and [fi.bct] for barrette.) I take these patterns as evidence that unstressed syllable truncation must (at least sometimes) come from the input to output mapping, rather than defective input representations, and thus that the grammar adopted to explain truncation in 12) and 13) is a plausible one.

This section has presented two analyses of phonological development in natural language learning, each built around what I have called an Intermediate Faith ranking. In each case,

\footnotetext{
${ }^{10}$ Given the rejection of gradient alignment constraints above, it is interesting to note that four syllable words still lose one of their unstressed syllables. If both stressed syllables must be preserved, and there are no gradient alignment constraints to count the number of syllables beyond any foot edge: why should 'alligator' and 'avocado' suffer syllable truncation at all? This type of problem has already been addressed in the literature on adult stress systems: Gouskova (2003) uses structural constraints on foot well-formedness such as STRESS-TO-WEIGHT to analyze metrical syncope in languages such as Tonkawa and Southeastern Tepehuan, which look rather similar to this English child's pattern. From this perspective, it may be that this latter stage of medial truncation reflects a desire for $\mathrm{H}$ rather than LL trochees, e.g. $\left(h a_{\mu \mu}\right)$ rather than $\left(h \varepsilon_{\mu} \cdot I I_{\mu}\right)$ in tableau $\left.15 b\right)$ i.
} 
learners present evidence of having acquired a marked structure - complex clusters in French, multiply-footed words in English - only in the privileged position of stressed syllables. The next three sections consider how a gradual constraint-based learner might derive these IF developmental stages.

\section{FREQUENCY OF VIOLATION AND THE PROBLEM OF IF STAGES}

The first learner to be considered here is the basic GLA approach (Boersma 1997, Boersma and Hayes (2001). As already laid out in the introduction, this learner will not pass through an IF stage like the ones discussed in section 2, at least not unassisted. Yet the GLA is a powerful approach to learning with ambitious goals, and it is appealing in many respects - as such, the purpose of beginning with the GLA is not to prove it wrong, but to understand why and where it can go awry. I suggest that the problem is the particular way that the GLA relies on errors and violations in its gradual learning, and this diagnosis will lead to the alternative proposal in section 4.

\subsection{Stochastic OT}

The original view of OT as laid out by Prince and Smolensky (1993/2004) considers constraint rankings to be ordinal. Two constraints in such an OT grammar can only stand in one of two relations $-\mathrm{A} \gg>\mathrm{B}$ or $\mathrm{B}>>\mathrm{A}-$ and there is no sense in which $\mathrm{A}$ can be ranked more or less above $\mathrm{B}$ or vice versa. ${ }^{11}$

In contrast, the constraint rankings that the GLA learns are what I will call numerical rather than ordinal. The GLA learns rankings where constraints have ranking values along a number line, so that every constraint is ranked not just above or below every other, but at a certain distance above or below every other. This is shown below, for some hypothetical constraints and ranking values:

17) The numerical view of OT constraint ranking

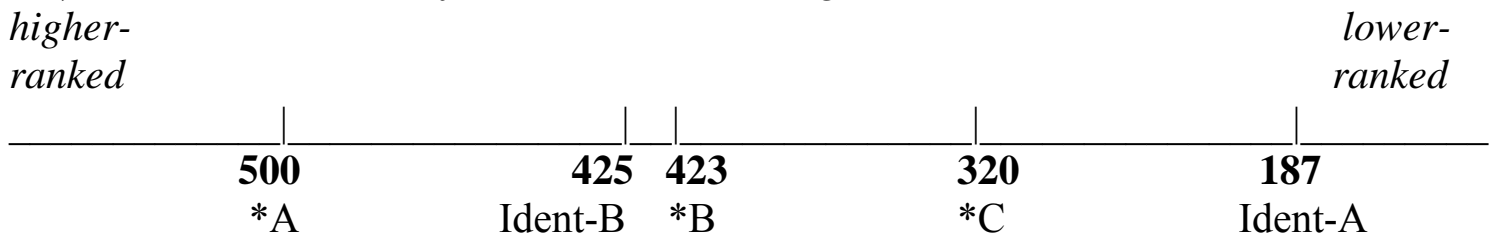

Furthermore, the grammar used by the classic GLA learner uses constraint rankings that are stochastic - they include some statistical noise. This noise is introduced by assuming that a constraint's ranking value does not just represent its single point on the scale, as in 17), but rather the midpoint of a normal (i.e. Gaussian) distribution of values. In other words: constraint

\footnotetext{
${ }^{11}$ In the Tesar and Smolensky $(1998,2000)$ view of learning, this property is relaxed slightly to allow a third relation of equal ranking, at least during the course of learning. Thus, the initial state constraint ranking assumed in much recent work is of the form $\{\mathrm{M}\}>\{\mathrm{F}\}$, where all markedness constraints are ranked above all faith constraints, but ranked equally with respect to each other.
} 
$\mathrm{X}$ 's ranking value is the place in the hierarchy that $\mathrm{X}$ is the most likely to sit, and the further away from $X$ 's ranking value you get, the less likely $X$ is to have that value. Each time a stochastic OT grammar is used, a single value is chosen for each constraint from its distribution of values - this choice creates a scale of single-point constraint values as in 18) below, which for practical purposes can be used by EVAL as a classic OT ranking:

18) A one-time ranking

\begin{tabular}{ccccc} 
& & & & \\
\hline 502 & 424.7 & 422.95 & 320.078 & 184.342 \\
$* \mathrm{~A}$ & $* \mathrm{~B}$ & Ident-B & $* \mathrm{C}$ & Ident-A
\end{tabular}

19) The ordinal version of 18)

$* \mathrm{~A}>>* \mathrm{~B}>>$ Ident-B $>>* \mathrm{C}>>$ Ident-A

Despite the fact that each run of this grammar relies on a single ranking that can be equated with a classic OT hierarchy, there are crucial differences between ordinal and numerical OT. The ranking values in (17) show that IDENT-B is ranked above $* \mathrm{~B}$, but only slightly above; this means that their distribution of values overlap considerably. In the one-time ranking of (18), for example, the value chosen from *B's distribution is in fact higher than the one chosen from IDENT-B's, so that for this use of the grammar, their ranking has been reversed. ${ }^{12}$ It is in this way that the relative distance between constraints makes numerical, stochastic OT different from the classic theory. It is also the conception of ranking values as numbers on a line that makes the Gradual part of the GLA possible, as we will see in the next section.

\subsection{How the GLA learns its stochastic OT grammar}

Like all other learning algorithms to be considered here, the GLA is error-driven. This means that it uses its current grammar to process language data and make errors; that it is the making of an error that triggers learning; and that the error guides it to reorganize its grammar in some way. To understand how the GLA learns, we must understand the format of these errors.

An error is an optimal candidate under the learner's current grammar that is not identical to the observed (i.e. heard) winner. As an example, imagine that the learner provides the input /A/ to their current grammar, and EVAL returns the output [C ]. The current grammar has thus made an error, illustrated in the tableau in 20):

\footnotetext{
12 The amount to which the curves of two constraints appear to overlap is a function not only of how similar their ranking values are but also how much random noise the system uses to choose one-time values: see Boersma 1997.
} 


20) An error
\begin{tabular}{|ll||c|c|c|c|c|}
\hline /A/ & & $*$ A & Ident-B & $* \mathrm{~B}$ & $* \mathrm{C}$ & Ident-A \\
\hline \hline (i) & A & $* !$ & & & & \\
\hline (ii) & B & & $* !$ & $*$ & & $*$ \\
\hline (iii) & C & & & & $*$ & $*$ \\
\hline
\end{tabular}

Our learner's specific task to establish why it made an error - that is, why its current grammar mapped /A/ to [C], and not to [A] - so we can ignore the rest of the candidate set and just compare the two output candidates $[\mathrm{A}]$ and $[\mathrm{C}]$. One way to make this comparison is the distilled form shown in 21):

21) Boiling down the information in tableau 20)

\begin{tabular}{|l|l|l|l|l|l|}
\hline$/ \mathrm{A} /$ & $* \mathrm{~A}$ & $* \mathrm{~B}$ & $* \mathrm{C}$ & Ident-A & Ident-B \\
\hline $\mathrm{A} \sim \mathrm{C}$ & $\mathrm{L}$ & $\mathrm{e}$ & $\mathrm{W}$ & $\mathrm{L}$ & $\mathrm{e}$ \\
\hline
\end{tabular}

In Prince (2002a), this distillation of candidate comparisons is called an Elementary Ranking Condition vector; here I will refer to them as ERC rows. What each cell in an ERC row reports is the preference of each constraint with respect to the winner and its rival loser candidate. The tableau in 21) shows that *A assigns a violation mark to the winner [A], and no mark to the loser $[\mathrm{C}]$, so we can say that $* A$ prefers the loser: thus the ERC row for the $\mathrm{A} \sim \mathrm{C}$ comparison contains an $\mathbf{L}$ in the *A column. Similarly, the third markedness constraint $* B$ assigns equal violation marks (in this case, none) to both the winner and loser candidates: thus, it prefers both winner and loser equally, and this equality puts an $\mathbf{e}$ in the *B column.

The Ls, Ws and es of an ERC row indicate the relevant discrepancies between the current and target grammars. The GLA's procedure of learning from these discrepancies is easy to describe: it promotes all constraints that prefer the winner (i.e. that assign a W in that error's ERC row) and demotes all constraints that prefer the loser (i.e. assign an L.) ${ }^{13}$ So in response to the error in 21), the GLA will now adjust ranking values as follows:

22) The GLA's response to the errors

\begin{tabular}{|l|l|l|l|l|l|}
\hline winner $\sim$ loser & $* \mathrm{~A}$ & ${ }^{*} \mathrm{~B}$ & $* \mathrm{C}$ & IDENT-A & IDENT-B \\
\hline $\mathrm{A} \sim \mathrm{C}$ & $\mathrm{L} \rightarrow$ & (no change) & $\leftarrow \mathrm{W}$ & $\leftarrow \mathrm{W}$ & (no change) \\
\hline
\end{tabular}

The amount by which each constraint is moved in response to an error is referred to as the learner's plasticity. If for example the learner's plasticity is currently 2, the actual re-ranking effect of 22) applied to the old grammar from 17) will be as in 23) below (previous ranking values are in regular font, new ones are in bold:

\footnotetext{
13 This particular method of choosing constraints to promote and demote is really only one of many GLAs considered in e.g. Boersma (1997) and Boersma and Hayes (2001). However, this is the one that these authors find works best - in particular, Boersma and Hayes (2001) diagnose this brand of GLA as the only one that produces the variation patterns they attempt to model. Therefore, I will refer to this re-ranking algorithm as "the GLA".
} 
23) The new GLA grammar

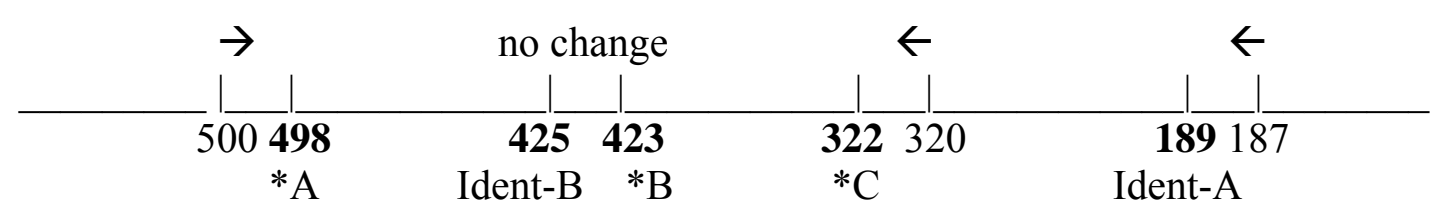

Note that the GLA learner does not attempt to resolve errors in any immediate way: the grammar in 23) is only very slightly less likely to map /A/ unfaithfully onto [C] as the previous grammar was. As Boersma and Hayes (2001) put it:

"The hypothesis behind the Gradual Learning Algorithm is that moderate adjustments of ranking values will ultimately achieve the right grammar." (p. 52)

$\ldots$ and that the extent of these gradual adjustments, over time, should mirror the frequency with which they have assigned Ws and Ls.

\subsection{The problem with IF stages}

This section walks through the way that frequency of violation prevents the GLA from reaching the IF stage. The example concerns the French complex onsets from $\$ 2.1$, as they most easily illustrate the problem.

We start with the initial state - the ranking that characterizes the state of the grammar before any learning has taken place. The basic assumption of nearly all the relevant learning literature is that the initial OT state is Markedness $>>$ Faithfulness (see, among many others, Smolensky 1996; Demuth 1996; Gnanadesikan 1995/2004.) The French IF stage is one seen halfway through development; in the target grammar the ranking of the relevant constraints is the reverse of the initial state: all $\mathrm{F}>>\mathrm{M}$. Thus, we have the three rankings below:

24) Three rankings
a. Initial state:
*COMPLEX $>>$ MAX/STRESSED, MAX
b. IF state:
MAX/STRESSED $>>*$ COMPLEX $>>$ MAX
c. Target state:
MAX $>>*$ COMPLEX $^{14}$

As indicated by the ranking in 24c), the target French stage is one that tolerates complex onsets in both stressed and unstressed syllables (recall table 4). The following is a schematic illustration of how this kind of lexicon will prevent the GLA, as seen so far, from reaching the IF stage:

\footnotetext{
${ }^{14}$ I assume that the ranking of the more specific faith constraint MAX/STRESSED is irrelevant here, although this is not always true: see Prince (1997); Lombardi (1999).
} 
25) GLA learning, with schematic French

a. Hypothetical observed winners:

$$
\text { bá blá biblá blibá }
$$

b. GLA Constraint movement, created by errors at initial state:

*COMPLEX: demoted by every word with any complex onset, i.e:

blá biblá blibá

MAX: $\quad$ promoted by every word with any complex onset, i.e.:

blá biblá blibá

MAX/STRESSED: $\quad$ promoted by every word with a stressed complex onset, i.e:

blá biblá

The upshot of $25 \mathrm{~b}$ ) is that no matter what the frequencies of word types, *COMPLEX and general MAX will fall and rise at the same rate during learning while specific MAX/STRESSED will rise slower: general MAX has the additional pressure of complex onsets deleted from unstressed syllables (blabá). Thus the second stage that this learner will reach is the one in 26):

26) The GLA's first new stage: MAX $>>*$ COMPLEX $>>$ MAX/STRESSED

Unfortunately, this is already the target stage: one that saves all complex onsets.

27) The mismatch between 43) and the observed intermediate stage:

\begin{tabular}{|l|l||c|c|c|}
\cline { 2 - 6 } \multicolumn{1}{c|}{} & \multicolumn{1}{l|}{$/$ blablá/ } & MAX/STRESSED & *COMPLEX & MAX \\
\cline { 2 - 6 } \multicolumn{1}{c|}{} & (i) babá & $* * !$ & & $* *$ \\
\hline IF stage winner & (ii) bablá & $* !$ & $*$ & $*$ \\
\hline GLA-learned winner & (ii) blablá & & $* *$ & \\
\hline
\end{tabular}

The core of the problem is this. When two faithfulness constraints are in a specific-to-general relationship like MAX/STRESSED- $\sigma$ and MAX, the frequency with which they demonstrate their need to be promoted will never push the more specific one up faster than the more general one. Yet to reach the IF stage by gradually changing ranking values, this is precisely what must happen.

\subsubsection{An alternative: no context-free faithfulness constraints?}

A reviewer points out that a GLA learner would receive a different set of violation profiles if its constraint set included two complementary faithfulness constraints: one targeting stressed segments and the other unstressed segments. In this alternative, the learner will be faced with two sets of errors, each supporting the promotion of the one of the faithfulness constraints: 
28) GLA learning of schematic French, with a revised constraint set

a. Initial state: $\quad$ *COMPLEX $>>$ MAX-IO/STRESSED, MAX-IO/UNSTRESSED

b. Hypothetical observed winners:

bá blá biblá blibá

c. GLA constraint movement, created by errors at initial state:

(i) *COMPLEX:

demoted by every word with any complex onset:

blá biblá blibá

(ii) MAX/STRESSED: $\quad$ promoted by every word with stressed complex onset:

blá biblá

(iii)MAX/UnSTRESSED: $\quad$ promoted by every word with an unstressed complex onset: blibá

As (28) shows, the errors that promote these two positional MAX constraints are entirely independent. What will determine which constraint the GLA learner promotes above *COMPLEX first, then, is purely a function of error frequency: that is, whether more target words are like (28bii) or like (28biii). Under the fairly reasonable assumption that French child-directed speech provides more stressed complex onsets than unstressed ones, our GLA learner could indeed reach the intermediate stage from section 2.1, as shown in (29):

29) The intermediate stage using revised constraint set:

MAX/STRESSED $>>*$ COMPLEX $>>$ MAX/UNSTRESSED

a)

\begin{tabular}{|l||c|c|c|}
\hline /biblá/ & MAX/STRESSED & *COMPLEX & MAX/UNSTRESSED \\
\hline (i) biblá & & $*$ & \\
\hline (ii) bibá & $* !$ & & \\
\hline
\end{tabular}

b)

\begin{tabular}{|l||c|c|c|}
\hline$/$ blibá/ & MAX/STRESSED & *COMPLEX & MAX/UNSTRESSED \\
\hline \hline (i) blibá & & $* !$ & \\
\hline (ii) bibá & & & $*$ \\
\hline
\end{tabular}

While this constraint can allow the learner to reach the desired intermediate stage, it also allows the possibility of the reverse pattern, in which MAX-UNSTRESSED is highest ranked and complex onsets are allowed only in unstressed syllables. Since such a pattern is attested neither in the developing grammars of children, nor in the typology of cross-linguistic adult grammars, it would seem that revising the constraint set into mutually-exclusive specific faith alternatives is unsatisfactory as a general solution to the learning of intermediate stages. 
To re-emphasize the main point, the question raised here is how closely tied the gradual learner should be to the frequency of the errors and violations it encounters. It is both welldocumented and unsurprising that the ambient frequency of some phonological structures affects the course and rate of their acquisition: for some pertinent examples, see Curtin and Zuraw, (2001), Levelt and van der Vijver (2004), Roark and Demuth (2000), Stites, Demuth and Kirk (2004). So the rest of this paper asks: how might a learner be gradual and influenced by violation frequencies, but still pass naturally through IF stages?

Before continuing, a sidenote on alternatives. A more elaborated version of the GLA could well be used to avoid problems caused by subset-superset relationships between faithfulness constraints such as this. The concrete proposal would be to equip the learner with three initial constraint rankings, with markedness very high, specific faithfulness in the middle, and general faithfulness very low. However, Hayes and Londe (2006: section 6.5) report that using a GLA learner alone is insufficient to restrictively capture the grammar of Hungarian vowel harmony, and they cite in particular a general faithfulness constraint (IDENT-IO/BACK) that 'inevitably rises too high in the grammar.' (See also Tessier 2007 for further discussion of difficulties for this option.) In section 6, I will return to the Gradual Learning Algorithm and its variants (albeit with a different grammatical framework) and argue that they are still insufficient to avoid superset language traps. But since the larger argument here is that our gradual learner should not proceed via gradual-reranking, I will first present my alternative proposal below.

\section{THE ERROR-SELECTIVE LEARNING APPROACH TO IF STAGES}

This section presents the Error-Selective Learner. ${ }^{15}$ In contrast to the previous approach, the ESL idea is to use a learning algorithm that knows nothing about frequency or gradualness, and to instead build these sensitivities into the way it chooses errors to learn from.

\subsection{Background on Error-Selective Learning}

The Error-Selective learner is built around an algorithm that, unlike the GLA, uses ordinal OT rankings. This algorithm is a blend of two recent and influential proposals: Biased Constraint Demotion (BCD: Prince and Tesar 2004) and Low-Faithfulness Constraint Demotion (LFCD: Hayes 2004). In what follows, I adopt much of the terminology of BCD, but I also rely crucially on a Faithfulness bias proposed only in LFCD. I will refer to this particular amalgamation as Multiply-Biased Constraint Demotion (MBCD.) ${ }^{16}$

To repeat the starting point: the learner with a grammar like the one in 30a) will make errors like the one represented in $30 \mathrm{~b})$ :

\footnotetext{
${ }^{15}$ Error-Selective Learning is proposed in a somewhat different format in Tessier $(2006,2007$.

${ }^{16}$ I will leave aside here the issues of how other biases from LFCD, such as 'Prefer Active', must also be used by this type of learner.
} 
30) Creating errors

a. An ordinal constraint ranking: $\quad * \mathrm{~A}>>* \mathrm{~B}>>$ IDENT-B $>>* \mathrm{C}>>$ IDENT-A

b. An ERC row created by using a) to map /A/ --> [C]:

\begin{tabular}{|l|l|l|l|l|l|}
\hline$/ \mathrm{A} /$ & $* \mathrm{~A}$ & $* \mathrm{C}$ & $* \mathrm{~B}$ & IDENT-A & IDENT-B \\
\hline $\mathrm{A} \sim \mathrm{C}$ & $\mathrm{L}$ & $\mathrm{W}$ & $\mathrm{e}$ & $\mathrm{L}$ & $\mathrm{e}$ \\
\hline
\end{tabular}

Given an ordinal view of OT grammar as in 30a), learning cannot be gradual re-ranking of constraints, up and down a GLA-style number line: instead, learning must mean changing the order of constraints. The goal of re-ranking for this learner is to 'resolve' the error - that is, to build a new ranking in which the produced loser [C] is less optimal than the target form [A]. Each cycle of learning creates a new grammar hypothesis, and this new grammar will cause a new set of errors and consequent ERC rows. While previous grammars are forgotten as soon as a new one is built, this learner retains its ERC rows in a table called the Support - thus, 30b) could be one of the many ERC rows in the learner's Support at one point in learning. An important aspect of the Error-Selective learner is that its MBCD algorithm always works with reference to the Support.

The logic used to resolve errors here comes from the Cancellation/Domination Lemma of Prince and Smolensky (1993: 148); described in Prince and Tesar (2004: 255) like this:

31) If every L-prefering constraint is ranked below some W-prefering constraint, our grammar will prefer the Winner to the Loser.

This lemma is the crux of the recursive Constraint Demotion Algorithm (CDA: Tesar and Smolensky, 1996, 1998, 2000; see also Prince 2002ab) and it also drives the core of MBCD and the algorithms it is based on. To rephrase the lemma a little: this algorithm will ensure that [A] is a more optimal output than [C] by installing constraints that are better satisfied by $/ \mathrm{A} / \rightarrow[\mathrm{A}]$ above constraints that are better satisfied by /A/ $\rightarrow[\mathrm{C}]$.

Building from the CDA, the re-ranking algorithms in Prince and Tesar (2004) and Hayes (2004) were designed with a particular goal: to be restrictive. To be maximally restrictive, a learner must choose a grammar that faithfully reproduces all the attested forms, and allows as few other forms as the constraint set allows. ${ }^{17}$ This is by no means an easy task - at the very least because many different constraint rankings will choose the same optimal input for a given output, and that each ERC row will only partially determine the nature of the new grammar to be learned. ${ }^{18}$ Space constraints do not permit a full explanation of how BCD or LFCD ensures

\footnotetext{
17 Put somewhat differently: a properly-restrictive grammar maps all of the Rich Base of potential inputs onto attested output forms.

${ }^{18}$ An incomplete history of restrictive linguistic grammar-building, in other frameworks as well as OT, includes but is not limited to Angluin 1980; Berwick 1985; Dresher 1999; Dresher and Kaye 1990; Gibson and Wexler 1994; Hayes 2004; Ito and Mester 1999; Jarosz 2006; McCarthy 1998; Prince and Tesar 2004; Pulleyblank and Turkel 1998; Smith 2000; Smolensky 1996; Tesar and Smolensky 1996, 1998, 2000; Tessier 2006, 2007.
} 
restrictiveness (see the original references for much more thorough discussion); the important ways that MBCD strives for restrictiveness will be introduced in section 4.2 as needed.

Since such algorithms resolve errors completely, they are not learners that go through any intermediate stages, such as the IF stages of section 2. This is not surprising: Prince and Tesar (2004) in particular are explicit in stating that their goal is not to model childhood acquisition, but rather to solve a formal learnability problem (namely how best to impose maximal restrictiveness on OT learning.) Any time MBCD is applied to the Support, it will learn everything there is to learn from each error, and ensure that error is never made again. Therefore, a pure MBCD constraint-demotion learner cannot learn gradually.

ESL is a way of using such an efficient re-ranking algorithm to learn gradually. The basic idea is to use Multiply-Biased Constraint Demotion to do what it does well (i.e. choosing the correct constraint ranking given a Support) but to slowly feed the right errors to the Support. Given that MBCD ensures restrictiveness by imposing ranking biases, ESL uses these same biases to select the best errors to learn from. Thus, each ESL learning cycle proceeds in two core steps: first, choosing a set of potential errors to learn from, and then applying MBCD and its biases to this set of errors until some learning has taken place. The result is a slightly modified ranking, and one new error added to the Support ${ }^{19}$ - and then the process begins again.

\subsection{Deriving the IF stage of French cluster acquisition}

In the ordinal OT view, the initial state of the French learning scenario has *COMPLEX ranked above both faithfulness constraints:

32) The French initial state (fragment):

*COMPLEX $>>$ MAX, MAX/STRESSED

The goal for our learner is to get from this initial state constraint ranking in 32) to the IF grammar from section 2.1.

\subsubsection{Making and storing errors}

As assumed throughout, the error-selective learner begins by taking target forms as inputs and using its current grammar to produce outputs. However when this learner makes an error, it does not immediately add the error to the Support; neither does this error immediately trigger reranking. Instead, as errors are made, their resulting ERC rows are put into a temporary storage area called the 'Error Cache'.

This is illustrated below in 33): one early French ranking, given in a), produces errors like the ones in b). In this example, I have added some additional plausible markedness constraints

\footnotetext{
${ }^{19}$ Or at least a small set of errors - see section 4.2
} 
relevant to the particular target segments being produced unfaithfully in the outputs. ${ }^{20}$ For the sake of space, these additional constraints have been abbreviated in the tables below, labeled with the particular segment that they penalize. Note that the dotted lines on the Error Cache table are meant to indicate the impermanence of this object.

33) a. An early grammar fragment of French:

$\left\{{ }^{*}\right.$ Complex, $*$ VcdAlveolarFric, ${ }^{*}$ Uvular, $*$ VoicedVelarStop, $*$ FrontRoundV $\}$ $>>$

$\{$ MAX-IO, MAX-IO/STRESSED $\}$

33) b. An Error Cache for the grammar in a)

\begin{tabular}{|c|c|c|c|c|c|c|c|c|}
\hline input & winner $\sim$ loser & *COMPLEX & $*_{\mathrm{Z}}$ & $*_{\mathrm{b}}$ & *g & $* \mathrm{y}$ & $\begin{array}{c}\text { MAX/ } \\
\text { STRESSED }\end{array}$ & MAX \\
\hline /gво/ & 'gвo 'ko & $\mathrm{L}$ & e & $\mathrm{L}$ & $\mathrm{L}$ & e & W & W \\
\hline /bri'ze/ & bsi'ze pi'ze: & L & $\mathrm{L}$ & $\mathrm{L}$ & $\mathrm{e}$ & e & e & $\mathrm{W}$ \\
\hline /gву.jo/ & gву.'jo ku. 'jo & $\mathrm{L}$ & $\mathrm{e}$ & L & $\mathrm{L}$ & $\mathrm{L}$ & $\mathrm{e}$ & $\mathrm{W}$ \\
\hline
\end{tabular}

While this grammar fragment is at the initial state with respect to these constraints, it is clearly the case that initial states of production do not necessarily correlate with a truely initial grammar - that is, some preliminary demotion of Markedness constraints has already taken place (see esp. Vihman \& Velleman 2003.) In the case of Théo - it seems reasonable to assume from the losers in (33b) that his grammar has demoted IAMB below TROCHEE to allow final stress, in addition to the rankings given in (33a). ${ }^{21}$ This means that his Support must already contain an error which brought about this demotion. To add this element of realism to this scenario, which will prove important to the workings of the error-selective learner, we will assume that the Support currently contains some error indicating this fact - for example an error made on the word for ‘baby', bébé:

34) The current Support, with one error from /beube/ 'baby'

\begin{tabular}{|c|c|c|c|c|c|c|c|c|c|c|}
\hline target & winner $\sim$ loser & TROCHEE & IAMB & $*^{*}$ COMP & $*_{\mathrm{z}}$ & $*_{\mathrm{b}}$ & $*_{\mathrm{g}}$ & $*_{\mathrm{y}}$ & $\begin{array}{c}\text { MAX } \\
\text { STRESSED }\end{array}$ & MAX \\
\hline /be'be/ & be'be $\sim$ 'bebe & $\mathrm{L}$ & $\mathrm{W}$ & $\mathrm{e}$ & $\mathrm{e}$ & $\mathrm{e}$ & $\mathrm{e}$ & $\mathrm{e}$ & $\mathrm{e}$ & $\mathrm{e}$ \\
\hline
\end{tabular}

Due to the confines of the printed page, this Support row in (34) should be interpreted as a fragment of the full ERC row. While this word is assigned es by all the featural markedness constraints used in (33b) above, it will have triggered learning on other markedness constraints

\footnotetext{
${ }^{20}$ In other words: each describes a class of segments missing from various languages: voiced velar stops are lacking in e.g. Dutch (Booij 1995), uvulars and front rounded vowels in e.g. English, voiced fricatives in e.g. Tagalog (Zuraw 2000.)

${ }^{21}$ It seems to be anecdotally acknowledged that the position of word stress is one of the first thing that children acquire in their phonology: that children make few errors in phonological stress, and overcome them much sooner than e.g. segmental or featural errors. This tendency will be derived if errors that demonstrate stress patterns like this one in (34) are added to the Support early on; why the ESL mechanisms are likely to choose stress errors earlier is returned to in section 4.3 .
} 
such as NONFINALITY, and so the current grammar will have demoted them along with TROCHEE accordingly.

\subsubsection{Choosing an error to learn from ${ }^{22}$}

As the learner continues to use its current grammar, the errors pile up and the Cache grows, while the Support is not updated and retains only its single error as in 34). To get anywhere more learning must eventually occur, which means that re-ranking must be triggered. In the ErrorSelective model, learning is triggered when a markedness constraint overcomes the 'Violation Threshold' - that is: when some constraint has assigned an L to more than x number of words in the Error Cache. ${ }^{23}$ This offending constraint is called the Trigger Constraint, because it has triggered learning. To take a very unrealistic but illustrative example: setting the violation threshold to 3 means that as soon as some markedness constraint assigns an L to three different winner $\sim$ loser pairs in the Error Cache, learning occurs.

In the Cache of $33 \mathrm{~b}$ ) above, adding that last error on 'oatmeal' means that *COMPLEX has now become a Trigger Constraint, and so a learning cycle begins. Step One of ESL is for the learner to choose a set of what are called Potential Best ERCs, being those ERC rows that might be learned from. This work is done by a sub-routine called the Error-Selection Algorithm (ESA); since our goal here is gradual learning, the ESA is designed to choose errors that will require as little change to the current ranking as possible. The ESA is defined in 35):

\section{5) ESL Step One: The Error Selection Algorithm}

\section{Choose as the Potential Best ERCs those rows in the Cache which: \\ a) have an $L$ assigned by the Trigger Constraint, and of those, the ones that \\ b) have the fewest Ls assigned by other Markedness constraints}

The two ESA criteria narrow down our set of three errors in the Cache of 33b) to two. All three errors have an L assigned by the Trigger Constraint *COMPLEX, so they all meet criterion (a). Criterion (b) rules out the last error 'oatmeal', since it has Ls assigned by three other markedness constraints; the other two errors remain as they each have Ls assigned by two other markedness constraints. Thus the ESA algorithm chooses our first two errors as the Potential Best ERCs set. (This is of course not an accident - the Cache in 34b) is designed to restrict this example's focus just to errors with complex onsets in the two relevant positions):

\footnotetext{
${ }^{22}$ I am grateful to an anonymous reviewer for critiques of this aspect of ESL, which I believe have improved the current version.

${ }^{23}$ This number is an independent parameter, whose setting is one way that this formal learning model might encode something like the amount of cognitive attention being paid to the learning problem. In other words: the lower the VT, the fewer errors the learner needs to be persuaded to learn a new grammar. See Tessier (2007) for some discussion.
} 
36) The Potential Best Errors, chosen by the ESA in Step One

\begin{tabular}{|c|c|c|c|c|c|c|c|c|}
\hline input & winner $\sim$ loser & $\begin{array}{c}* \text { COMPLEX } \\
\text { Trigger }\end{array}$ & $*_{\mathrm{z}}$ & $*_{\mathrm{B}}$ & $*_{\mathrm{g}}$ & $* \mathrm{y}$ & $\begin{array}{c}\text { MAX } \\
\text { STRESS }\end{array}$ & MAX \\
\hline /gвo/ & 'gво 'ko & L & $\mathrm{e}$ & $\mathbf{L}$ & L & $\mathrm{e}$ & $\mathrm{W}$ & $\mathrm{W}$ \\
\hline /bsi'ze / & bьi'ze pi'ze: & $\mathbf{L}$ & $\mathbf{L}$ & $\mathbf{L}$ & e & $\mathrm{e}$ & $\mathrm{e}$ & $\mathrm{W}$ \\
\hline
\end{tabular}

The crucial difference between the two rows in 36) is in their faithfulness violations - in particular, whether the specific faithfulness constraint MAX/STRESSED assigns a $\mathrm{W}$ or not. In the first error 'gros', markedness has caused deletion of a stressed onset segment so that both MAX constraints assign a W; for the second error 'brisé', markedness has caused the deletion of an unstressed segment so the specific MAX constraint is assigned an e.

\subsubsection{Learning from errors using $M B C D$}

Step Two of the ESL cycle is to apply the MBCD algorithm to build a new grammar including both the old Support AND the chosen set of Potential Best ERCs. The central idea of Multiply-Biased Constraint Demotion, like the BCD and LFCD algorithms it is built from, is to give the learner a set of constraint ranking biases, which the learner assumes up until the ERC rows provide evidence to the contrary. Building a constraint ranking is a series of cycles of adding constraints to strata - starting at the top and continuing until there are no more constraints to be ranked. In building each stratum, the learner aims to install all constraints that its biases want highest-ranked, and put off the installation of all other constraints until it has to.

The MBCD algorithm that I adopt here has two important ranking biases. First is the by-nowfamiliar markedness $>>$ faithfulness bias which makes the first pass of ranking decisions; second is a bias for ranking more specific IO-Faith constraints above more general ones, proposed by Smith (2000), and implemented in LFCD by Hayes (2004). Both of these are crucial to seeing how our learner with the Support in 51) will reach the IF stage grammar. ${ }^{24}$

With these biases, the MBCD algorithm builds a grammar by performing a total ordering of the constraints from scratch, in a way that will resolve all the ERC rows it is given. In Step Two, the Error-Selective learner's goal is to use the MBCD algorithm's ranking biases to install constraints, and thereby resolve errors in the Support, up until the point that one Potential Best $E R C$ row has been resolved. We will see immediately how this short-term goal will ensure gradual learning of the sort that derives IF stages.

\footnotetext{
${ }^{24}$ Given the importance of the specific $>>$ general IO-faith bias here, it must be noted that Prince and Tesar (2004) present good reasons to explicitly reject such a bias, using different principles to determine which IO-faith constraints to install in any stratum. For reasons of space, I simply assume here that this bias can indeed be implemented; for the details see Hayes (2004), Tessier (2007).
} 
37) ESL Step Two: Applying MBCD (first pass)

a) Begin with the set of ERC rows that includes both (i) all ERC rows in the Support and (ii) all the Potential Best ERC rows.

b) Apply MBCD to this set, installing constraints in strata until one of the ERC rows in (aii) has been resolved

In the present example, MBCD begins with the set of constraints from 33) and 34) above, all as yet unranked, and the errors in 38) below to resolve:

38) Errors for the $M B C D$ at the beginning of Step Two

\begin{tabular}{|c|c|c|c|c|c|c|c|c|c|c|}
\hline input & winner $\sim$ loser & TROCHEE & IAMB & *COMP & $*_{\mathrm{Z}}$ & $*_{\mathrm{b}}$ & $*_{\mathrm{g}}$ & $* \mathrm{y}$ & $\begin{array}{c}\text { MAX } \\
\text { STRESS }\end{array}$ & MAX \\
\hline /be'be/ & be'be 'bebe & $\mathrm{L}$ & $\mathrm{W}$ & $\mathrm{e}$ & $\mathrm{e}$ & $\mathrm{e}$ & e & e & $\mathrm{e}$ & $\mathrm{e}$ \\
\hline /gво/ & 'gro 'ko & $\mathrm{e}$ & e & $\mathrm{L}$ & $\mathrm{e}$ & $\mathrm{L}$ & $\mathrm{L}$ & $\mathrm{e}$ & $\mathrm{W}$ & $\mathrm{W}$ \\
\hline /bsi'ze/ & bsi'ze pi'ze: & $\mathrm{e}$ & $\mathrm{e}$ & $\mathrm{L}$ & $\mathrm{L}$ & $\mathrm{L}$ & $\mathrm{e}$ & $\mathrm{e}$ & $\mathrm{e}$ & W \\
\hline
\end{tabular}

MBCD then proceeds to build each stratum in the constraint ranking as follows. ${ }^{25}$

- Stratum1: (i) install all the Markedness constraints that prefer no losers:

resulting stratum 1: *FronTROUNDV, IAMB

These are the only constraints we can install under (i): the other Markedness constraints each prefer at least one loser, and the last two are not markedness constraints. This first principle is the main way in which the $\mathrm{M}>\mathrm{F}$ bias is instantiated in MBCD.

Having installed *y has not yet resolved any errors (since it did not assign any Ws), but installing IAMB has. With this W-preferring constraint at the top of the hierarchy, it necessarily outranks all the L-preferring constraints in the ERC row for 'bébé', and so by 31) we now that this error has been resolved. Once an error has been resolved, the MBCD algorithm stops looking at that error's Ws and Ls:

39) Errors for the MBCD after Stratum 1 built:

\begin{tabular}{|c|c|c|c|c|c|c|c|c|c|c|}
\hline input & winner $\sim$ loser & TROCHEE & IAMB & *COMP & $*_{\mathrm{z}}$ & $*_{\mathrm{b}}$ & $* g$ & $* \mathrm{y}$ & $\begin{array}{c}\text { MAX } \\
\text { STRESS }\end{array}$ & MAX \\
\hline the'bet & be'be- 'bebe & $t$ & $W$ & e & e & e & e & e & e & $\mathrm{e}$ \\
\hline /gro/ & 'gro 'ko & e & e & $\mathrm{L}$ & $\mathrm{e}$ & $\mathrm{L}$ & $\mathrm{L}$ & $\mathrm{e}$ & $\mathrm{W}$ & $\mathrm{W}$ \\
\hline /bsi'ze/ & bsi'ze $\sim$ pi'ze: & $\mathrm{e}$ & $\mathrm{e}$ & $\mathrm{L}$ & $\mathrm{L}$ & L & $\mathrm{e}$ & e & $\mathrm{e}$ & $\mathrm{W}$ \\
\hline
\end{tabular}

Now the algorithm moves onto the next stratum, beginning again with the first principle, and since the first error is now ignored we can install another Markedness constraint:

\footnotetext{
${ }^{25}$ Note that this walk-through is merely a synthesis of the core of BCD, augmented with a bias from LFCD, and certainly does not do justice to either.
} 
- Stratum2: (i) install all the Markedness constraints that prefer no losers: resulting stratum 2: TROCHEE

And then we move on:

- Stratum 3: (i) install all the M constraints that prefer no losers

(but each prefers a loser)

Since (i) can install no constraints, MBCD moves onto the second decision principle, which has two parts:

- Stratum3: (ii) find all the Faithfulness constraints that prefer a winner:

con'd

(and there are two: MAX/STRESSED and MAX)

(iii) install (one of) the W-preferring F-constraints that is the most specific resulting stratum 3: MAX/STRESSED

The (ii) part of this principle is an extension of the $M>>F$ bias - since we are forced to include a faithfulness constraint in this stratum, we should at least include one that will resolve some error so that the next stratum has a better chance of containing $M$ constraints. The (iii) part imposes the second bias, Specific-Faith $>$ General-Faith, and in this case it chooses MAX/STRESSED. ${ }^{26}$

With just these two strata of constraints installed, we can now see that this new grammar will no longer make the error on 'gros' given in (38): MAX/STRESSED will rule out the loser for

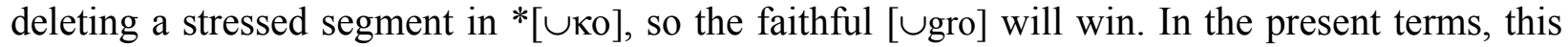
ERC row has been resolved. And now our short-term Step Two goal has been met. We have built a ranking that resolved one of the Potential Best ERC rows; we have learned something new. With this learning accomplished, the Error-Selective learner finishes Step Two by removing all the remaining Potential Best ERC rows from its learning datum except the one it has resolved.

40) ESL Step Two: Applying MBCD (final)

a) Begin with the set of ERC rows that includes both (i) all ERC rows in the Support and (ii) all the Potential Best ERC rows.

b) Apply MBCD to the set in (a), installing constraints in strata until one of the ERC rows in (aii) has been resolved

c) Remove all of (ii) except the error resolved in (b)

d) Continue applying MBCD to the remaining Support ERC rows until termination

\footnotetext{
${ }^{26}$ Looking at just these two constraints, it is obvious which one is more specific from their names and definitions, but this is not always the case: see Prince and Tesar (2004), Tessier (2007).
} 
41) The new Support, after one Potential Best ERC row has been resolved

\begin{tabular}{|c|c|c|c|c|c|c|c|c|c|c|}
\hline input & winner $\sim$ loser & TROCHEE & IAMB & *COMP & $*_{\mathrm{Z}}$ & $*_{\mathrm{B}}$ & $*^{*} \mathrm{~g}$ & $* \mathrm{y}$ & $\begin{array}{c}\text { MAX } \\
\text { STRESS }\end{array}$ & MAX \\
\hline the'bet & be'be - 'bebe & $\mathrm{E}$ & $W$ & e & e & e & e & e & $\mathrm{e}$ & e \\
\hline tgrot & 'gto_ko & e & e & $E$ & e & $E$ & $\mathrm{E}$ & e & $W$ & $W$ \\
\hline
\end{tabular}

Since at this point all errors have been resolved, the MBCD algorithm is free to rank the remaining constraints as its biases please - i.e., all remaining $\mathrm{M}>>\mathrm{F}$.

- Stratum 4 (i) install the Markedness constraints that prefer no losers:

resulting stratum 4: *COMPLEX, *UVULAR, *VCDFRIC, *VCDVELARSTOP

- Stratum 5: (i)install the Markedness constraints that prefer no losers:

(but each prefers a loser, so:)

(ii) find all the Faithfulness constraints that prefer a winner:

(and there is only one remaining, MAX, so:)

resulting stratum 5: MAX

And since there are no more constraints left to be ranked, the MBCD algorithm has succeeded, and it terminates.

42) The final result of applying $M B C D$ to the error set in 38)

$\{*$ FrONTROUNDV, IAMB $\}$

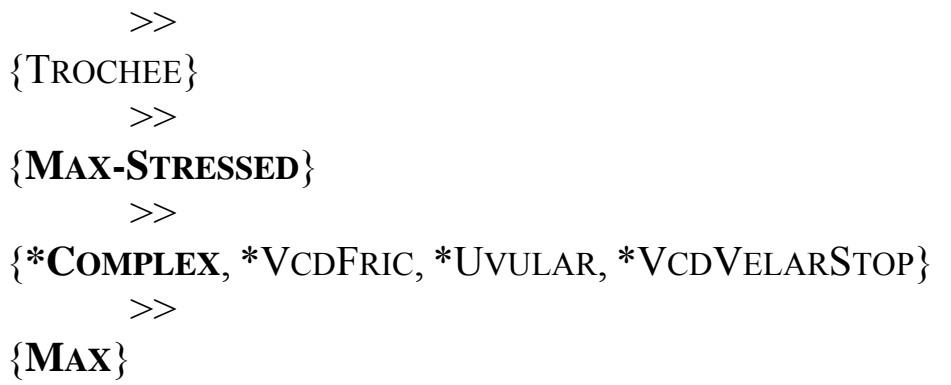

Having arrived at the grammar in 42), the Error-Selective Learner has reached the goal of this section. This ranking that MBCD has built includes the necessary rankings to produce the attested French IF stage with respect to complex onset simplification (see the bolded constraints). Compared to the previous grammar in 32), this ranking now protects complex clusters in stressed syllables, but still rules them out in unstressed ones.

At the end of Step Two, the learner now has a new ranking and a new error learned from. To keep track of the knowledge that moved it from the rankings (32) to (41), it must now update its Support, to include that ERC row that was resolved. In the present case, that was the ERC row for 'gros', resolved after Stratum 3 was built. Conversely, the learner must also clear their Cache 
of all the errors made by the previous grammar. ${ }^{27}$ These two updates are Step Three of the ErrorSelective Learning process; after this, the learner begins using their new grammar, making new errors that are accumulated in the Cache, and waiting until the Violation Threshold is overcome by a new constraint and the cycle begins again.

\section{3) ESL Step Three: Updating Error Memory}

a) Add to the previous Support that ERC row which was resolved in Step Two (b) b) Empty the Cache

\subsection{Frequency of violation and Error-Selective learning}

To take a step back: what we have just seen is that the Error Selective learner, using a nongradual re-ranking algorithm, can nevertheless progress from the initial state to an IF stage. It does so by choosing to learn only from a small subset of errors that it has already made, and it uses its ranking biases in part to make those choices.

While the Error-Selective learner is guided in all its learning decisions by violation profiles, its sensitivity to violation frequency is rather more complicated than that of the GLA - and its sensitivity to markedness vs. faithfulness violation frequencies is crucially different. Violation Thresholds, and the ESA criterion (b) that favours errors with the fewest other Ls, conspire to predict that order of acquisition should broadly mirror markedness violation frequency. The more errors that a markedness constraint assigns Ls to, the more of those L-assigned errors will pile up in the Cache, so the more likely it is to either be a Trigger Constraint, or to be one of the few Ls assigned to a members of the Potential Best Error set. Note that this sensitivity accords with the tendency discussed at the beginning of this section (see footnote 21): that the basic facts of phonological stress, such as the relative ranking of TROCHEE vs IAMB, appear to be learned earlier across languages than featural markedness. Since every word has stress, but not every word necessarily contains a particular marked segment or featural combination, more Ls assigned by these basic metrical constraints will pile up in the Cache faster than for constraints like *FrontRoundVOWEL or *UVULAR, and so are more likely to overcome the Violation Threshold and/or be added to the Support.

On the faithfulness side, however, the MBCD ranking bias makes the choices. In fact, this biases the learner towards choosing errors with the most Ws assigned by faith constraints (compare the number of faith Ws assigned to the Potential Best ERCs in 36). The MBCD biases themselves choose which of the Potential Best Errors to resolve first, and they will choose to demote markedness below specific faith constraints first - even though the general faith constraints assign Ws more often.

It must be emphasized that while the Error-Selective learner can go through an IF stage, it is by no means guaranteed to do so. This indeterminacy comes first from the the Error-Selection Algorithm, which chooses the Potential Best ERC rows. In this example, the ESA chose errors

\footnotetext{
${ }^{27}$ For why the Cache must be cleared, see Tessier (2007).
} 
with clusters in both stressed and unstressed syllables, precisely because each of these errors had the fewest other markedness problems given the then-current grammar. If a different error had been included in the Cache - one with an unstressed onset cluster and fewer assigned Ls otherwise - it would have been chosen as the lone Best ERC row, and its inclusion in the Support might well have derived a new grammar with the target ranking, MAX $>>*$ COMPLEX. No IF stage would have been created in between.

Given this element of randomness, it should be noted as a positive sign that some IF stages are probably not shared by all learners of a language. This French example is a case in point, for while the two children in Rose's (2000) study went through this IF stage, the Kehoe and DeboveHilaire (2003) results provide evidence for a few children, going through the same stage with respect to two particular obstruent-glide clusters only, and no evidence of a positional asymmetry at all for the majority others. Determining whether some such stages are nearly universal within a particular language, and whether the ESL approach can predict that universality (from the constraint set and the input frequencies facts of that language) is an empirical and open question.

\subsection{Variation between rankings and Error-Selective learning}

An attentive reader, particularly one with restrictive grammar-building in mind, may have noticed something suspicious about the ranking in 42). What are the consequences of all the markedness constraints that were demoted down to Stratum 4, along with *COMPLEX? Some of these demotions are inescapable: once 'gros' has been added to the Support, all of the markedness that its loser eliminated must be allowed into the grammar. But why has the learner demoted the constraint against [z]? When learning began, all Potential Best Errors were at stake, so MBCD was prevented from installing *VOICEDALVEOLARFRICATIVE in the top stratum by the error on 'brisé'. But once 'gros' was resolved, 'brisé' and all the other PBEs were ignored, and subsequently cleared from the Cache. Thus is the final Support, there is no evidence for this constraint's demotion! Does this mean that the ESL is doomed to be unrestrictive, despite the MBCD's explicit goals?

Thankfully no - because ESL is crucially about storing errors, not grammars. In the ranking of 42), the learner has indeed built a grammar that allows more marked structures than it has stored evidence for. However, a central idea of Error-Selective Learning is that building rankings is always an easy task (getting from ERC rows to grammars via MBCD) - what the learner hesitates to do is build permanent representations of learning data (the ERCs themselves.) If the MBCD algorithm were run again on the current Support, the learner will have no recourse to the previous Cache and its old errors, and so indeed will be able to install *VoicedAlVEOLARFriCATIVE in the top stratum. Under these assumptions, then, the complete Error-Selective Learner will be required to run their current Support through MBCD - merely to clear out any vestigal rankings for which there is no stored evidence in its ERC rows. There are 
multiple reasons this might be a good idea beyond the current issue; I will return to another one in section $5 .^{28}$

A final remark about the nature of Error-Selective Learning: the goal of this approach is not to find maximally-informative data for the learner to attend to - in comparison to e.g. recent proposals by Pearl $(2007,2008$.) In fact, as a reviewer points out, the aim of ESL is in fact to select uninformative data, of a certain sort, so as to delay fully accurate learning of the target phonology.

\section{The CONSTRAint WeIGHTING APPROACH TO IF STAGES ${ }^{29}$}

This section introduces a rather different answer to the question of how to use violation frequencies to reach an Intermediate Faithfulness stage. Instead of using an ordinal OT learning algorithm that gradually accepts errors, this section returns to a gradual, GLA-like learner but instead learns a different kind of grammar: a Harmonic Grammar (HG: Legendre et al 1990; Smolensky and Legendre 2006, Pater, Bhatt and Potts 2008.) Summarizing one key result from Jesney and Tessier (2007, to appear), I will first show that this GLA-like learner that uses HG evaluation will in fact reach IF stages, even without a bias for Specific $>$ General faith. However this learner is still very sensitive to frequency of violation, because it uses gradual reranking. Thus, section 6 will demonstrate how this learner is still susceptible to frequencyinduced dangers, because it cannot revise its learning from previous errors.

\subsection{Weighted constraints as an alternative theory of grammar}

The theory of Harmonic Grammar, like Optimality Theory, is a hypothesis about how grammars use constraints to assess linguistic forms. The Harmonic Grammar view of constraint interaction (laid out in Prince and Smolensky 2004: 236 as an alternative to OT) is that each constraint has a numerical weight, and the harmony of each output candidate is the sum of its constraint violations each multiplied by their weights. Following Smolensky and Legendre (2006) and Pater et al (2007), I will use an HG grammar in which constraint violations are negative numbers, so that EVAL returns as optimal the candidate with the highest harmony, meaning the number closest to zero (see also Jesney and Tessier 2007; Keller 2006; Prince 2002a.)

To see how constraint ranking and weighting differ, consider the example in 44) below. This normal two-by-two OT tableau can also be interpreted in a constraint weighting grammar if each

\footnotetext{
${ }^{28}$ One other application of these re-runs is to so-called U-shaped development, where child grammars sometimes regress to what appears to be a less marked grammar after some time of having a more advanced one (see Stemberger, Bernhardt and Johnson 2001; Bleile and Tomnlin 1991; Macken and Ferguson 1983; Menn, 1976, 1983). Under this approach, regressions could be brought about by running the current Support through the MBCD algorithm and discovering that some rankings are not justified by any stored errors, prompting a return to a more restrictive grammar.

${ }^{29}$ I am grateful to Joe Pater, Karen Jesney and Marcin Morzycki for insightful and challenging discussion of the issues in this section, and to an anonymous reviewer for careful comments and suggestions.
} 
constraint is given a weight (in the top row). The final column shows the 'score' for each output - each of its violations multiplied by its constraint weight:

44) Weighting $\neq$ Ranking

\begin{tabular}{|c|c|c|c|c|}
\hline \multirow{4}{*}{ OT winner } & Weights: & 2 & 1 & \multirow{2}{*}{$\begin{array}{c}\text { Score (sum of } \\
\text { violations } * \text { weights) }\end{array}$} \\
\hline & Input & Con1 & Con2 & \\
\hline & Output 1 & & $* * *$ & $0(2)+-3(1)=-3$ \\
\hline & Output 2 & * & & $-1(2)+0(3)=-2$ \\
\hline
\end{tabular}

In the familiar OT ranking, Output2's violation of CoN1 is fatal, and so Output1 is the winner. But when considered by a HG ranking, Output1's three violation of low-weighted CON2 is enough to rule it out and choose Output 2 as the winner. Following Pater et al (2007), I interpret constraint violations as negative integers. ${ }^{30}$

The present paper cannot hope to adequately discuss the range of differences between an ordinal OT system and a weighted Harmonic Grammar, or their consequences: for some of the additional recent literature on the topic, see Coetzee and Pater to appear; Flemming 2001, Jesney 2006, Keller 2006; Tesar 2007. Whatever the final consensus about their relative merits, further investigation of weighted constraint grammars seems warranted, and has already been fruitful to the investigation of natural language typology, acquisition and implementation. The result relevant to this topic, reported in Jesney and Tessier (2007, to appear) is summarized below: that a weighted constraint grammar and a GLA-like learner, will naturally pass through Intermediate Faith stage even without a Specific $>>$ General faithfulness bias.

\subsection{Deriving the French IF stage using weighted constraints and GLA-like learning}

In this view of grammar, every language is characterized by the weights on each of its constraints. We can therefore imagine these weights on a number line, just like the ranking values of the GLA's stochastic OT:

45) repeated from 17)

\begin{tabular}{ccccc} 
& & & & \\
\hline $\mathbf{5 0 0}$ & 425 & 423 & 320 & 187 \\
$* \mathrm{~A}$ & Ident-B & $* \mathrm{~B}$ & $* \mathrm{C}$ & Ident-A
\end{tabular}

The diagram in 45) can be interpreted as either a stochastic OT grammar or a weighted constraint grammar: the difference will only be in how EVAL uses these numbers to choose optimal input-output mappings. And since a weighted constraint grammar looks like 45), it can also be learned using the same core of the GLA technique already seen. Recall how the GLA

\footnotetext{
${ }^{30}$ Notice that constraint order in a HG tableau is not as visually instructive as in OT: unlike the candidate 'winnowing' that can be applied left-to-right when reading an OT tableau, every constraint's violations in an HG system may need to be considered to find the optimal output.
} 
learns: given an ERC row with its Ws, Ls and es, the GLA promotes every constraint that prefers the winner and demotes every constraint that prefers the loser.

Thus, we can feed an initial set of constraint values and an initial Support (set of errors) to a GLA-like learner and ask it to gradually increase and decrease these values to fit those errors. What is different from previous sections is how new errors and grammars are evaluated: to choose the loser for any winner, the constraint 'values' from the number line in 54) must be interpreted as weights rather than rankings. This EVAL task can be simulated using the LinearOT evaluation method in recent versions of Praat (this method is described in the Praat manual as an implementation of Keller (2006)'s LinearOT.) ${ }^{31}$ In this mode, the learner moves its constraints values up and down in response to errors, and the effects of new constraint values are evaluated using a constraint weighting grammar. This will be illustrated at each crucial stage of learning, beginning with the initial state.

In this simulation, Markedness constraints all begin with an initial weight of 100 , and all faithfulness constraints with an initial weight of $0 .^{32}$ To make the example as simple as possible, I fed the learner only the three crucial constraints from the French example: *COMPLEXONSET, MAX-IO and MAX-IO/STRESSED. The two errors I gave the learner were gros and brisé, which provide complex onsets in a stressed and unstressed syllable respectively.

46) The two errors

\begin{tabular}{|l|l|c|c|c|}
\hline target & winner $\sim$ loser & *COMPLEX & MAX/STRESSED & MAX \\
\hline gros & 'gro $\sim$ 'ko & $\mathrm{L}$ & $\mathrm{W}$ & $\mathrm{W}$ \\
\hline brisé & bьi'ze $\sim$ pi'ze: & $\mathrm{L}$ & $\mathrm{e}$ & $\mathrm{W}$ \\
\hline
\end{tabular}

Plasticity was set throughout the simulation at 0.1 and both errors were presented to the learner equally often. Here is how the grammar in Praat looked initially:

47) The initial grammar

$\begin{array}{lll}\text { a. Constraint weights: } & \text { *COMPLEXONSET } & 100.00 \\ & \text { MAX } & 0.00 \\ & \text { MAX/STRESSED } & 0.00\end{array}$

\footnotetext{
${ }^{31}$ As noted by the term GLA-like used throughout, this LinearOT learner has a slightly different update rule from the OT-GLA method. Despite Praat's use of the Keller term, I have chosen not to use the term 'LinearOT learning' here, because I use the labels OT and HG to refer to grammars that use ranked constraints with strict domination on the one hand and weighted constraints on the other; for present purposes this seems a crucial distinction to keep in the terminology.

${ }^{32}$ For why faith should start as low as zero in this model, see Jesney and Tessier (to appear).
} 
b. The mappings:

\begin{tabular}{|c|c|c|c|}
\hline /gво/ & $\begin{array}{c}* \text { COMPLEX } \\
100\end{array}$ & $\begin{array}{c}\text { MAX } \\
0\end{array}$ & $\begin{array}{c}\text { MAX/STRESSED } \\
0\end{array}$ \\
\hline 'gво & $*$ & & \\
\hline 'ko & & $*$ & $*$ \\
\hline
\end{tabular}

\begin{tabular}{|c|c|c|c|}
\hline /bьi'ze/ & $\begin{array}{c}* \text { COMPLEX } \\
100\end{array}$ & $\begin{array}{c}\text { MAX } \\
0\end{array}$ & $\begin{array}{c}\text { MAX/STRESSED } \\
0\end{array}$ \\
\hline bьi'ze & $*$ & & \\
\hline pi'ze: & & $*$ & \\
\hline
\end{tabular}

c. The constraint weight sums:

$$
\begin{aligned}
& -1 *(100)=-100 \\
& -1 *(0)+-1 *(0)=\mathbf{0}
\end{aligned}
$$

$$
\begin{aligned}
& -1 *(100)=-100 \\
& -1 *(0)=\mathbf{0}
\end{aligned}
$$

When this mode of learning is applied to these constraint weights and errors, the weights change just as the ranking values did in section 3, in direct proportion to their violation frequencies. General MAX prefers the winner in both errors, so its weight is increased every time an error is made; MAX/STRESSED prefers the winner only in the second error, so its weight will be increased half as often. Thus, MAX rises twice as fast as its specific counterpart.

After between 400 and 500 trials of learning on this grammar, the ranking values have changed sufficiently to choose a different set of optimal outputs. A typical state of the grammar at this point is illustrated below, after 500 trials - and this grammar represents the French IF stage.

48) The grammar after 500 trials

a. Constraint weights: *COMPLEX 54.778

MAX 45.222

MAX/STRESSED $\quad 19.582$

b. The mappings:

\begin{tabular}{|c|c|c|c|}
\hline /gьо/ & $\begin{array}{c}* \text { COMPLEX } \\
54.778\end{array}$ & $\begin{array}{c}\text { MAX } \\
45.222\end{array}$ & $\begin{array}{c}\text { MAX/STRESSED } \\
19.582\end{array}$ \\
\hline 'gьо & $*$ & & \\
\hline 'kо & & $*$ & $*$ \\
\hline
\end{tabular}

\begin{tabular}{|c|c|c|c|}
\hline /bьi'ze/ & $\begin{array}{c}* \text { COMPLEX } \\
54.778\end{array}$ & $\begin{array}{c}\text { M AX } \\
45.22\end{array}$ & $\begin{array}{c}\text { MAX/STRESSED } \\
19.582\end{array}$ \\
\hline bri'ze & $*$ & & \\
\hline pi'ze: & & $*$ & \\
\hline
\end{tabular}

c. The constraint weight sums:

$-1 *(54.778)=-54.778$

$-1 *(45.222)+-1 *(19.582)=-64.804$

$$
\begin{aligned}
& -1 *(54.778)=-54.778 \\
& -1 *(45.222)=-45.222
\end{aligned}
$$

This new grammar in 48) retains onset clusters in a stressed syllable only. Looking at the constraint weight sums, we see that this change in optimal output comes from the collective strength of specific and general MAX: while each is less powerful than markedness on its own, their combined strength is enough to 'gang up' on *COMPLEX, and so prevent deletion in *[ko]. This 'gang' effect is precisely what OT strict domination prohibits in constraint interactions. 
Since this grammar is still making errors (on 'brisé'), it will continue to learn, i.e. adjust its constraint weights. After about 650 or so trials, the learner has found a stable grammar that does not produce any further errors, illustrated below:

49) The grammar after 650 trials
a. Constraint weights: MAX
*COMPLEX:
MAX/STRESSED
19.582

b. The mappings:

\begin{tabular}{|c|c|c|c|}
\hline /gво/ & $\begin{array}{c}\text { MAX } \\
51.986\end{array}$ & $\begin{array}{c}\text { *COMPLEX } \\
48.014\end{array}$ & $\begin{array}{c}\text { MAX/STRESSED } \\
19.582\end{array}$ \\
\hline 'яво & & * & \\
\hline 'ko & $*$ & & $*$ \\
\hline
\end{tabular}

c) The constraint weight sums:

\begin{tabular}{|c|c|c|c|}
\hline /bьi'ze/ & $\begin{array}{c}\text { MAX } \\
51.986\end{array}$ & $\begin{array}{c}* \text { COMPLEX } \\
48.014\end{array}$ & $\begin{array}{c}\text { MAX/STRESSED } \\
19.582\end{array}$ \\
\hline bsi'ze & & $*$ & \\
\hline pi'ze: & * & & \\
\hline
\end{tabular}

$-1 *(48.014)=\mathbf{- 4 8 . 0 1 4}$

$-1 *(51.986)+-1 *(19.582)=-71.568$

Compared to the IF stage, this final grammar has increased the weight of general MAX so that it is greater than that of *COMPLEXONSET, while the value of MAX/STRESSED has stayed exactly the same. Now that MAX's constraint weight is sufficiently large, even a single deletion is now enough to outweigh *COMPLEXONSET, so the cluster in the unstressed syllable of 'brisé' will surface faithfully. This is therefore the end-state grammar of French.

\subsection{How the GLA-like learner of Harmonic Grammars reaches IF stages}

Given that the learner maps directly between violation frequencies and constraint movement, why was it able to produce the IF stage in the above simulation? The answer comes from the nature of additive constraint interaction: in a sense, it is because every constraint violation of a candidate contributes towards its harmony. In an OT grammar learned by this GLA-like learner, general and specific constraints rise in value until general MAX overcomes markedness, when both errors in e.g. 46) are resolved and the target state is achieved. But as the weights of general and specific MAX rise in the HG system, there comes a time when general MAX is still not important enough to outweigh markedness, but both general and specific MAX are strong enough to gang up on markedness, and this results in the IF stage. 
50) Necessary weighting inequalities for an IF stage in a Harmonic Grammar $w$ (Markedness $)>w($ GeneralFaith $)$ $w($ SpecificFaith $)+w($ GeneralFaith $)>w($ Markedness $)$

A further result is that this learner reaches the IF stage without a ranking bias between faithfulness constraints; its only initial weighting bias is that markedness outweighs IOfaithfulness. ${ }^{33}$ The subset/superset relationship between MAX/STRESSED and MAX is not something the learner must know to find the IF stage - instead, the fact that their violation profiles stand in this relationship is enough for the stage to emerge.

Two points should be emphasized before moving on from this result. The first is that, in contrast to the Error-Selective Learner already seen, this gradual HG learner is required to pass through each IF stage along the way to a target language in which a marked structure is allowed in all contexts. ${ }^{34}$ As mentioned already, the empirical evidence for ubiquitous IF stages is not at all clear, but perhaps little should be made of this result until better data has been acquired.

A different point is that this HG learner's relies crucially on the GLA style of learning to reach an Intermediate Faith stage. A logical alternative, which will be discussed in section 7.2, is a Harmonic Grammar learner used its ERC rows in the spirit of Recursive Constraint Demotion, using them to learn weighting inequalities such as 'the weight of MAX must be greater than that of *COMPLEXONSET'. If so, the HG learner would be as non-gradual as ever, and one error like 'brisé' would be enough to skip over the IF stage just as in section 3.

\section{FREQUENCY OF ViOLATION AND THE PROBLEM OF WINNER MiSPARSES}

As has been emphasized, the HG learner of section 5 and ESL of section 4 differ how they are gradual. What any GLA-style learner does gradually is change its constraint values: their relative distance from each other represents the core of the learner's grammatical knowledge. From the ESL viewpoint the situation is almost opposite: what are learned gradually are the errors, as stored both in the Cache and Support, and the current grammar represents nothing but a particular Support-to-ranking mapping done by MBCD. While the ESL learner uses its memory of previous errors to create ever newer grammars, a GLA-like learner has no such memory. The errors that brought it to the present state are neither stored nor even directly recoverable from that ranking.

The GLA-style learner must therefore trust that the frequency with which it gets its errors and their violation profiles will never lead it too far astray, that it will never need a memory for how it reached the current grammar. What I will argue in this section is that one class of learning situations makes such a memory crucial. In these cases, learning from violation frequencies without such a memory can bring the learner not to the wrong intermediate stage, but rather the

\footnotetext{
${ }^{33}$ And that IO-faith begins at zero.

${ }^{34}$ Unless a language had a marked structure in only the complement of the privileged context - e.g., that all complex onsets were found only in unstressed syllables.
} 
wrong end-state grammar. This argument is germane to the goals of this paper because it suggests a fundamental problem with learning via gradual, numerical re-ranking and violation frequencies. While this problem exists for any GLA-stlye learner, whether using OT or Harmonic Grammar, the two case studies in this section will use HG tableaus to keep up the comparison with section 5 .

The general outline of the problem is this. Learners often have to make assumptions about hidden structural information, such as syllable or foot structure, before they can assess an error's Ws and Ls. If the current grammar makes the wrong assumptions about structure, the resulting ERC rows can include what I will call 'winner misparses', and these misparses can lead the learner to a superset language. This kind of misleading evidence from frequency of violation is again the result of constraints whose contexts are in subset/superset relationships - and these can occur even when two markedness constraints are at issue. The two examples provided in the next two sections are hypothetical, but given the fairly standard constraints assumed in each case, the claim is that superset languages could be found in children's early phonologies if the right target grammar intersected with some particular statistical properties of a child's early lexicon. However, the more general point made in this limited space is that such superset languages are certainly possible, if not probable, and thus are a challenge which any learner should be prepared to face.

Winner misparses can happen to any of the learners discussed here; the question is how a learner can recover from them, at the point when a winner misparse has been resolved. These examples show that even a cautious learner cannot take its errors at face value, and therefore that a successful gradual learner must still store errors and be able to reason about them later. From the present perspective, this is something that the ESL alone is well-equipped to do.

\subsection{Winner misparses and relations among Faith constraints violations ${ }^{35}$}

Suppose that the learner is acquiring a language with coda devoicing: so that onset segments can be voiced or voiceless, while codas can only be voiceless. In the previous sections of this paper, such a set of weights would have been characterized as an IF stage, ${ }^{36}$ but it also characterizes the end-state of learning for languages like Dutch in which coda voicing is neutralized. As we saw in 50), an IF pattern requires two weighting inequalities. To translate to the contextual neutralization of voicing rather than complex onsets, we can plug the constraints of Lombardi (1999) on voicing into the inequalities, as in 51) below:

51) A target grammar - contextual neutraliztion of voicing in coda obstruents $W^{*}$ VOICEDOBSTRUENT $>$ WIDENT[VOICE] $w($ IDENT[VOICE]-ONSET $)+w$ IDENT[VOICE] $>*$ VOICEDOBSTRUENT

\footnotetext{
${ }^{35}$ I am grateful to John McCarthy for suggesting this example to me.

${ }^{36}$ Such an intermediate stage of obstruent devoicing is reported for the English-learning child in Smith (1973).
} 
Assuming the $\mathrm{M} \gg \mathrm{F}$ initial state, the learner of this language will initially devoice voiced obstruents under the pressure of *VOICEDOBS so that a target form like ['kibla] will come out unfaithfully as ['kipla]. Under one other assumption we will see in a moment, this means that they will create ERC rows like 52) below:

52) Learning onset voicing: the right ERC row

\begin{tabular}{|l|c|c|c|}
\hline winner $\sim$ loser & $*$ VOIC EDOBS & IDENT[VOICE]-ONS & IDENT[VOICE] \\
\hline 'ki.bla $\sim$ 'kI.pla & $\mathrm{L}$ & $\mathrm{W}$ & $\mathrm{W}$ \\
\hline
\end{tabular}

The crucial assumption encoded in 52) is that the voiced target segment that gets devoiced is syllabified as an onset. This assumption comes from other rankings in the grammar that determine the optimality of each syllabification: for example, the relative ranking of STRESS-TOWeIGHT (which is violated by a stressed light syllable like $[\cup \mathrm{kI}]$ ) and NoCoDA. As the two tableaus below show, getting the right ERC row in 52) requires that $w$ NoCODA is greater than $w$ STRESS-TO-WEIGHT (numerical weights here chosen arbitrarily):

53) Two different syllabifications of the ERC forms ${ }^{37}$

\begin{tabular}{|c|c|c|c|c|c|c|c|}
\hline /'kibla/ & $\begin{array}{c}\text { STRESS- } \\
\text { TO-WEIGHT } \\
110\end{array}$ & $\begin{array}{c}\text { NoCODA } \\
90\end{array}$ & & / kIbla/ & $\begin{array}{c}\text { NoCODA } \\
110\end{array}$ & $\begin{array}{c}\text { STRESS- } \\
\text { TO-WEIGHT } \\
90\end{array}$ & \\
\hline 'ki.bla & $* !$ & & $=-110$ & 'kI.bla & & * & $=-90$ \\
\hline 'kib.la & & $*$ & $=-90$ & 'kıb.la & $* !$ & & $=-110$ \\
\hline
\end{tabular}

But what if our learner currently has a greater weight assigned to STRESS-TO-WEIGHT rather than NoCODA? This will cause them to represent this same error on ' $\kappa \mathrm{I} \beta \lambda \alpha$ ' differently, not as in 52) but as in 54) below:

54) Learning onset voicing with the wrong ERC row

\begin{tabular}{|l|c|c|c|}
\hline winner $\sim$ loser & *VOICEDOBS & IDENT[VOICE]-ONS & IDENT[VOICE] \\
\hline 'kib.la $\sim$ 'kip.la & L & $\mathbf{e}$ & W \\
\hline
\end{tabular}

Comparing the right and wrong ERC rows above, the important difference is already apparent: IDENT(VOICE)-ONSET does not assign a W in 54), because the segment which is unfaithful to voicing is not an onset. So even though the HG learner does not need any biases to get to the IF stage, the error in 54) will still cause prosblems - because the learner does not realize that the correct end-state grammar resolves this error.

An illustration of this problem begins with an early ranking, at which markedness is above faithfulness and general faithfulness has already climbed somewhat above specific faith. Errors like 54) will cause the demotion of *VOICEDOBS and the promotion of general IDENT[VCE].

\footnotetext{
${ }^{37}$ I am leaving aside some technical discussion about how the current grammar assigns hidden structure to winners: see esp. Tesar and Smolensky (2000). What is crucial here is that the same current grammar syllabifies both the winner form and the loser, so that within an ERC row, syllabification will remain constant.
} 
55) The re-ranking effect of the ERC row, at the early stage:

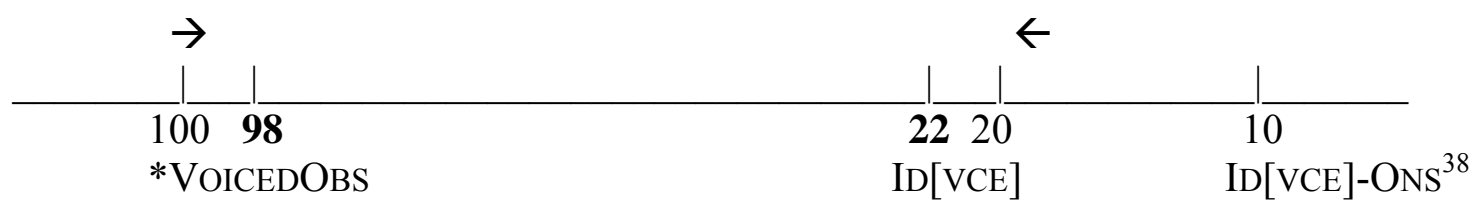

When armed with errors like those in 52), we have already seen that the HG-GLA will reach the IF stage, in which both faith constraints can gang up on *VoICEDOBSTRUENT, but general IDENT-VOICE cannot do it alone. For a language like Dutch where only onset obstruents can be voiced, an IF grammar in fact characterizes the target -- and yet this current grammar's beliefs about syllabification mean that the learner is still making errors:

56) The continuing error at the IF stage

\begin{tabular}{|l||c|c|c|c|}
\hline /'kibla/ & $\begin{array}{c}\text { (VICEDOBS } \\
60\end{array}$ & $\begin{array}{c}\text { ID(VOICE) } \\
50\end{array}$ & $\begin{array}{c}\text { ID(VOICE)-ONSET } \\
10\end{array}$ & \\
\hline \hline winner: 'kib.la & $* !$ & & & $=-60$ \\
\hline loser: 'kip.la & & $*$ & & $=-50$ \\
\hline
\end{tabular}

Even though the learner has reached the target ranking, it has not resolved this error because of its mistaken syllabification. And so learning continues, *VoICEDOBSTRUENT continues to be demoted, and general IDENT-VOICE continues to rise:

57) The continued effect of the winner misparsed ERC row, at the IF stage:

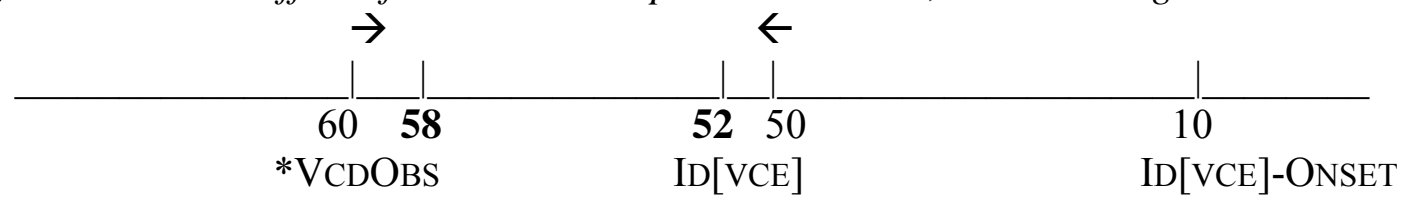

This learning will continue until one of two things happen: the weight of general IDENT(VOICE) gets above *VOICEDOBSTRUENT, or the learner learns the right weightings of STRESS-TO-WEIGHT and NoCODA. The danger is that if the former happens first, the learner will have reached the wrong final state:

58) The incorrect final grammar wIDENT-[VOICE] $>w^{*}$ VCDOBS $>$ wIDENT-[VOICE]-OnSET

\footnotetext{
${ }^{38}$ Although the error in 55) does not cause the HG-GLA learner to change the weighting of IDENT[VCE]-ONSET, I have given it a value greater than the initial zero weight. This is because it seems safe to assume that the language will provide learners with forms other than 54) in which voiced obstruents do occur in an unambiguous onset position (e.g. ['brk.la] or ['r.ba]), causing errors in which ID-ONSET does indeed prefer the winner and so has its weight increased.
} 
The pathology here is this first inequality: with wIDENT-VOICE being greater than $w^{*}$ VOICEDOBSTRUENT, voiced obstruents will be incorrectly protected outside of onset positions (e.g. $/ \mathrm{kib} / \rightarrow *[\mathrm{kib}]$.)

\subsection{Escaping the superset grammars of winner misparses}

We have seen thus far that a learner, working from misleading errors, can be deluded into choosing a less restrictive grammar than the intended target. This is just as much a problem for the Error-Selective BCD learner from section 4: with a misyllabified error like 54) in the Support, an ordinal learner can just as easily end up with the OT version of the grammar in 58). The issue is whether the learner has a way to undo this error.

The Error-Selective Learner that has acquired the incorrect grammar in 58) will only have done so because it has added the error of 54) to its Support - and because 54) fails to reveal that ranking a specific faith constraint above markedness is sufficient to resolve this error. Because the problem is thus localized, it can be fixed - all that must happen is an update to the Support.

The crucial step for the Error-Selective learner will be adopting the correct language-specific ranking of NoCODA $>$ STRESS-TO-WEIGHT. When this ranking has been changed, the learner now knows something new about the target language that they did not know when they assigned structure to their Support's winners. Thus, we can equip the ESL learner with a requirement that from time to time, it should re-assign hidden structure to the winners and losers in their ERC rows using the current grammar, and then re-assign Ws and Ls to those forms that have changed in any way. In the present case, the new grammar in which NOCODA dominates STRESS TO WEIGHT will resyllabify all intervocalic clusters as complex onsets regardless of their stress, so that [kib.la] will be resyllabified as [ki.bla] and the ERC row in 54) will be updated to look like 59) (repeated below from 52):

\section{9) The correct ERC row}

\begin{tabular}{|l|c|c|c|}
\hline winner $\sim$ loser & *VOICEDOBS & IDENT[VOICE]-ONS & IDENT[VOICE] \\
\hline 'kı.bla $\sim$ 'kı.pla & $\mathrm{L}$ & $\mathrm{W}$ & $\mathrm{W}$ \\
\hline
\end{tabular}

With all intervocalic voiced obstruents resyllabifed in this way, the Support will now be rid of any errors that provide evidence for the OT ranking of IDENT[VOICE] $>>*$ VOICEDOBSTRUENT. The next time the Error-Selective learner runs MBCD on this new Support with errors like 59), the familiar ranking bias for installing specific faith constraints rather than general ones will be sufficient to ensure that the learner reaches the correct OT ranking as in 60):

60) Correct ranking learned by MBCD given errors like 59) IDENT[VOICE]-ONS $>>$ *VOICEDOBS $>>$ IDENT[VOICE]

Note that the MBCD algorithm will not know how many times it made the old, misleading error from 54), nor could it do anything with that knowledge even if it did. Once the Support has the new syllabification for ['kr.bla], this learner has forgotten 54), and the next cycle of re- 
ranking will immediately result in the correct OT grammar. Notice also that the Error-Selective learner will return to the more restrictive grammar in 60) even after it has already stopped making errors on forms like ['kI.bla]. The trigger for adopting the more restrictive grammar is not due to anything about voiced obstruents per se, but rather a consequence of the learner's check on the match between Support and grammar.

In contrast, a GLA-style learner does not have any straightforward way of moving beyond the superset grammar of 58). Suppose that, at some point after 58) have been adopted, the learner gradually switches the ranking of the two structural constraints, so that now NoCODA does outweigh STRESS-TO-WEIGHT. Now what should it do about the winner misparse ERC row for 'kibla'? The constraint with the incorrect position is IDENT(VOICE), and faithfulness to voicing has nothing in principle to do with either of the two markedness constraints whose rankings have been reversed, except for their indirect effect on the errors that caused re-ranking. How now should the learner realize that some of its earlier errors should not have prompted the re-ranking of *VOICED OBSTRUENT and IDENT-VOICE? This is a way in which an incremental algorithm like the GLA's disconnect between errors and their re-ranking effects seems to cause real problems. In fact, this learner has no way of demoting below a particular constraint - it only moves constraints along its numerical scale, without reference to the (ordinal) position of any others. And this learner's problem is again related again to violation frequencies, because its learner remembers how many times each constraint was shown to need promoting or demoting, rather than why it needed to be promoted or demoted or which constraints it needed to outrank. As it stands, it is not clear how a GLA-style learner should incorporate any of the necessary reasoning into its method of gradual re-ranking. ${ }^{39}$

\subsection{Winner misparses and relations among markedness constraint violations}

This section presents a different winner misparse trap in which learning straight from frequency of violation can cause problems. While again illustrating the central point of this paper, it also differs in at least two important ways from the previous example. First, it uses a different kind of hidden structure, relying on feet rather than syllables. ${ }^{40}$ As a reviewer points out, mis-syllabifications like those in the previous section will not present a trap for the learner if, following Côté (2000), Jun (1995), Steriade (1999) and others, phonotactic constraints are characterized not with reference to syllable structure but rather by position in the segmental string. Under this view, the constraint IDENT[VOICE]/ONSET will be re-defined as IDENT[VCE]/PRE-SONORANT (for example), so that the ERC row [kibla $\sim$ kipla] will be assigned a W

\footnotetext{
${ }^{39}$ One possibility, originally suggested to me by Kie Zuraw, might be that the GLA learner could include a persistent pressure to demote all IO faithfulness constraints - or perhaps in this case, all general faithfulness constraints - at all times. (See also a related suggestion in Hayes (2004b)'s OTSoft Manual.) The gist of this proposal would be that over time, any general IO-faithfulness constraints would always be sinking back down the scale of values (or weights). Two crucial issues for any such approach, once fleshed out, would be (a) how a learner would know that it should stop trying to demote general faithfulness, in a language where e.g. IDENT[VOICE] really does dominate *VOICED OBSTRUENT, rather than forever cycling through error generation and resolution, and (b) whether the resulting error patterns would match attested developmental stages.

${ }^{40}$ Thanks to Joe Pater for suggesting this particular example to me.
} 
by both faithfulness constraints regardless of syllabification. Second, this example triggers a winner misparse using markedness constraints, to demonstrate that it is not faithfulness constraints themselves that are the ultimate cause of this problem.

In this example, the language in question has an allophonic alternation between aspirated and unaspirated voiceless stops, according to which the aspirates appear in foot-initial position and the plain stops appear elsewhere. (These are nearly the facts of English aspiration. ${ }^{41}$ ) To capture this basic allophonic pattern, I will use the two markedness constraints in 61) below:
a) *UnASPIRATED Voiceless Stop/Foot-INitial
(shortened to AsP/FT-INIT)
b) *ASPIRATE
(shortened to *ASP)

The constraint in 61a) is presumably a positional strengthening constraint (see esp. Smith 2002), and the one in 61b) is a context-free markedness constraint, necessary to derive the lack of aspirates in many languages. In a classic OT grammar, this kind of allophony comes from a ranking of specific markedness $>>$ general markedness $>>$ faithfulness. As it turns out, this ranking is simply mirrored in the HG system of constraint weights:

Necesssary HG and OT grammars for allophonic aspiration

a) OT: ASP/FT-INITIAL $>>* A S P>>$ IDENT-ASP

b) HG: wASP/FT-INITIAL $>w^{*}$ ASP $>$ wIDENT-ASP

As in previous sections, we begin with the initial state of both Markedness constraints weighted equally high and IDENT-ASP low (i.e. at zero). With this initial state, the learner can reach this grammar in 62) by making de-aspiration errors, like the one in 63) below. This error will come about if the more general markedness constraint (*ASP) has a weight slightly greater than the specific one (ASP/FT-INITIAL), so that aspiration is removed from a foot-initial segment:

63) Learning the distribution of voicing: the right ERC row

\begin{tabular}{|l|c|c|c|}
\hline winner $\sim$ loser & *ASPIRATE & ASP/FT-INITIAL & IDENT(ASP) \\
& 101 & 99 & 0 \\
\hline$\left[\mathrm{bo}\left({ }^{\mathrm{t}} \mathrm{t}\right.\right.$ ego $\left.)\right] \sim[\mathrm{bo}($ 'tego $)]$ & $\mathrm{L}$ & $\mathrm{W}$ & $\mathrm{W}$ \\
\hline
\end{tabular}

From this ERC row, the learner will increase the weight of ASP/FT-INITIAL and decrease the weight of *ASPIRATE, and so the right ranking will quickly be reached. But as with the previous example of syllabification: this ERC row is only as right as the learner's current belief about foot structure. The output form in 63) above, bot égo, was chosen precisely because it contains a classic structural ambiguity - is this medial stressed syllable the result of an initial iambic foot, or a final trochaic one? The choice between these two analyses will be made by the relative weights of footing constraints, i.e. TROCHEE vs. IAMB. If currently the learner's grammar

\footnotetext{
${ }^{41}$ The complications raised by aspiration in e.g. word-initial position as in $\left[p^{h} o\right]$ tato, and in morphologicallycomplex contexts, will not be dealt with here: see e.g. Jensen 1993; Davis 2003.
} 
includes the incorrect weighting wIAMB $>$ TROCHEE, then the learner will have constructed the following incorrect ERC row:

64) The wrong assignment of foot structure, and the wrong ERC row ${ }^{42}$

\begin{tabular}{|l|c|c|c|}
\hline winner $\sim$ loser & *ASPIRATE & ASP/FT-INITIAL & IDENT(ASP) \\
& 101 & 99 & 0 \\
\hline$\left[\left(\right.\right.$ bo't $\left.\left.^{\mathrm{h}} \mathrm{e}\right) \mathrm{go}\right] \sim\left[\left(\mathrm{bo}^{\prime}\right.\right.$ te $\left.) \mathrm{go}\right]$ & $\mathrm{L}$ & $\mathrm{e}$ & $\mathrm{W}$ \\
\hline
\end{tabular}

What will be the result of this winner misparse in 64) above? As a result of this error, the HGGLA learner will increase the weight of *ASP and decrease the weight of IDENT(ASP) only - it will leave the value of AsP/FT-INITIAL unchanged, since in this learner's eyes the aspirated stop of bot 'égo is not foot-initial. If the learner's incorrect assumption about the foot structure of medially-stressed three-syllable words persists long enough, errors of this sort will prompt the learner to invert the relative weightings of IDENT(ASP) and *ASP, resulting in an end-state grammar as in 65):

65) Eventual result of HG-GLA learning from the wrong ERC row in 64) $w$ ASP/FT-INITIAL $>w$ IDENT(ASP) $>w^{*}$ ASPIRATE

Compared to the target language in 62), this grammar is in fact a superset language. Rather than allophonic aspiration, this grammar creates positional neutralization of aspiration: at the beginning of a foot, voiceless obstruents are correctly required to be aspirated, but anywhere else they incorrectly show contrastive aspiration:

66) Lack of restrictiveness in the grammar of 65)

\begin{tabular}{|c||c|c|c||c|}
\hline$/$ bo'dek $^{\mathrm{h}} \mathrm{o} /$ & $\begin{array}{c}\text { ASP/FT-INITIAL } \\
99\end{array}$ & $\begin{array}{c}\text { IDENT(ASP) } \\
60\end{array}$ & $\begin{array}{c}* \text { ASPIRATE } \\
40\end{array}$ & \\
\hline \hline * bo'dek $^{\mathrm{h}} \mathrm{o}$ & & & $*$ & $=-\mathbf{4 0}$ \\
\hline bo'dego & & $* !$ & & $=-60$ \\
\hline
\end{tabular}

As with the previous example, the Error-Selective learner will retain this superset grammar only as long as it has the ERC row of 64). Once the learner establishes that Trochee outranks Iamb, their re-parsing of winners like [bo' $\mathrm{t}^{\mathrm{h}} \mathrm{ego}$ ] will assign the correct foot structure as in 63). The next time the MBCD algorithm is fed the revised Support, its first bias for installing Markedness constraints whenever they do not prefer Losers will now install ASP/FT-INITIAL in the first stratum, resolving the error right away. With all cases of aspiration resolved, the ranking bias will now be able to install *ASPIRATE above IDENT(ASP), yielding the correct grammar in 62a).

\footnotetext{
${ }^{42}$ A reviewer points out that using this constraint Asp/Ft-Initial allows for the possibility of the error in (64) being the right parse in some language - that is, a language which builds iambs, but which requires aspiration among just those unstressed stops which are foot-initial. In the absence of any such typological evidence, it may be that this contextual markedness constraint is not the right one for the task.
} 
For the GLA, however, there is again no clear way in which reversing the values (or weights) of IAMB and TROCHEE should or could cause any re-ranking of constraints on aspiration.

\section{CONCLUDING DisCUSSION}

\subsection{Summarizing the results across learning alternatives}

This paper represents one attempt to combine the results of natural language acquisition and learnability theories. It has demonstrated that a class of attested intermediate stages in phonological development cannot be produced by an OT learner that re-ranks its constraints in direct proportion to the frequency of constraint violations and satisfaction in its errors. More generally, this paper has brought into focus some issues facing a constraint-based learner which aims to be gradual, restrictive and sensitive to frequency.

While the paper began with the most basic OT-GLA algorithm, its eventual result has been to propose a very different method of constraint-based gradual learning: Error-Selective Learning using Multiply-Biased Constraint Demotion. Section 2 introduced the evidence from L1 developmental stages; these cases suggest that learners must be able to innovate grammars that are more restrictive than their targets, in a way that contradicts the frequency with which constraints are violated. The resulting claim has been that the Error-Selective learner is better equipped to get from available errors to restrictive rankings, predominantly because its sensitivity to violation frequency is mediated through its ranking biases. In addition, section 6 introduced evidence from potential end-state superset grammars to suggest that no matter how restrictive a gradual re-ranking learner is, it must still be able to undo previous rankings in a nongradual way. These examples were used to argue that the Error-Selective learner's reliance on the Support's stored errors is justified, and in fact necessary.

One result in the literature that is related to the present discussion is that of Pater (to appear), which reports a certain cluster of ERC rows for which the OT-GLA fails to converge on a grammar. This example demonstrates a particular problem that the GLA has in handling what Dresher (1999) calls the Credit Problem: in this case, determining which W-preferring constraints need to be ranked above which L-preferring ones. On the one hand, the dilemma of winner misparses is certainly related to the Credit Problem - because one thing a learner like the GLA cannot do is reverse its poor placement of credit for winner loser pairs after it has made errors and forgotten them. Pater (to appear) demonstrates that a GLA-like learner that uses constraint weighting does converge on a grammar for this data. On the other hand, section 6 demonstrated that winner misparses cause difficulties for the GLA's method of gradual learning, not for a particular method of grammatical evaluation (constraint ranking vs. weighting.)

\subsection{A final learning alternative}

As a reviewer rightly points out, this paper has not yet discussed a fourth logical possibility in the search for both a restrictive grammar and a gradual learner. The approach supported here is a combination of an OT grammar and a non-gradual learning algorithm, namely MBCD. The two 
alternatives to which it has been compared both involved gradual GLA-like learning, combined with grammars that either rank or weight constraints, using OT or HG respectively. The remaining combination is a learner that builds Harmonic Grammars and yet does not use a gradual algorithm, but rather one that resolves its errors as MBCD does. One might well ask whether an Error-Selective HG learner, using a non-gradual algorithm to re-weight constraints, could achieve the same results as the ESL of section 4 - or even better results.

To my knowledge, the only learner on the market which resolves errors to build a Harmonic Grammar is found in Potts, Pater, Bhatt and Becker (2008). They show how a HG can be interpreted as a linear system, so that the problem of grammar learning can be solved using the simplex algorithm, a highly-efficient optimization tool from applied mathematics. Their initial method, implemented in the online software tool HaLP simply learns a Harmonic Grammar that resolves a set of errors (if possible) while minimizing the total constraint weights. Furthermore, a newer version of HaLP can impose weighting biases on constraints $^{43}$, such as a bias to keep faith weighted as low as possible - thereby making the HaLP learner restrictive as well.

However, it is in fact not possible to simply re-imagine Error Selective Learning using HG by replacing the MBCD algorithm with the HaLP method. The reason is that the Error-Selective Learning approach proposed in section 4 is in part tied to the workings of MBCD itself, which in turn are tied to properties of Optimality Theory and the strict ranking of constraints. Step Two of ESL, spelled out in its final form in (40) of section 4.2.3, applies MBCD to a set of potential ERC rows until one has been resolved, and then discards all the others. Recall again the two errors that the learner had to choose between in (39): gros, with a complex onset cluster protected by both MAX/STRESSED and MAX, and gruau, with a complex onset protected only by general MAX. In this relevant case, the ESL procedure allows the specific $>>$ general IO-faith bias of MBCD to choose which potential ERC row is resolved first - this was spelled out in the reasoning that gets the French learner from tables (39) to (40), and chooses gros.

How could this procedure be mimicked by a non-gradual HG learner, attempting to choose between potential ERC rows? Given a HaLP-style algorithm which preferred to keep faithfulness constraints weighted low, an error like gros would indeed prompt the learner to successfully build a grammar with the weighting conditions from section 5's example (50): the weights of specific and general faith constraints would be increased sufficiently for them to gang up on *COMPLEXONSET and protect onset clusters only in stressed contexts. But how could this ESL's Step Two be revised to choose gros as the right ERC row to learn from, rather than gruau? In the OT-ESL approach, the decision is made by both the MBCD's bias for specific $>>$ general faith, and the installation of MAX/STRESSED into an OT ranking, whose presence in a stratum $n$ ensures that no subsequent constraints installed in stratum $n+1$ or further down will ever unresolve the error. Even if the HaLP learner was further biased to keep the weights of general faith constraints even lower than specific ones, mimicking the second MBCD bias from section 4, the learner

\footnotetext{
${ }^{43}$ Within the linear programming method, one method of biasing constraints to be low-weighted is to increase their coefficients in the objective function; see Potts, Pater, Bhatt and Becker (2008).
} 
would still need a way to choose between gros and gruau using that bias. And since a Harmonic Grammar can only choose between two candidates when every constraint's weighted contribution has been assessed, this learner would need to determine that the sum of every constraint's weight will be lower if we choose gros rather than gruau. Choosing the right Potential Best Errors would mean determining the total constraint weights created by adding each PBE to the existing Support in turn, and finally choosing to retain just those ERC rows that result in the smallest total weights.

In this light, the HG-ESL approach does not seem like a promising alternative to the OT version proposed in section 3. Unlike the GLA-style HG learner of section 5, the Error-Selective HG learner will still require a specific $>$ general faith bias, and it additionally requires the calculation of multiple entire potential grammars on every cycle of learning. However, in the spirit of this paper's broader goals, I consider one interesting avenue of future research to include possible alternative methods of online HG learning, using something like Error-Selective Learning, and their potential benefits and consequences.

\subsection{Current conclusions}

The largest goal of this paper is to reveal that frequencies are not always reliable information to learn from - and that frequency information needs to be mediated by a grammaticallyinformed learner to correctly steer (and sometimes re-evaluate) development. In addition, this work raises a set of new questions about the kinds of empirical data needed to distinguish between learning proposals in the natural language context. Finding some of these answers may indeed prove difficult, but they represent the ultimate test for this research program.

\section{REFERENCES}

ANGLUIN, DANA. 1980. Inductive inference of formal languages from positive data. Information and Control 45: 117-135.

Apoussidou, DiAnA (2007). The learnability of metrical phonology. LOT-dissertation series, \#148. [http://www.fon.hum.uva.nl/diana/The_Learnability_of_Metrical_Phonology.pdf]

Beckman, JiLl N. 1998. Positional Faithfulness. Doctoral dissertation, University of Massachusetts, Amherst.

BERWICK, ROBERT. 1985. The acquisition of syntactic knowledge. Cambridge, MA: MIT Press.

Bleile, Ken And J. Bruce Tomblin. 1991 'Regressions in the Phonological Development of Two Children. Journal of Psycholinguistic Research 20 no. 6, 483-499.

Boersma, PAUL. 1997. Functional Phonology: Formalizing the interactions between articulatory and perceptual drives. Ph.D. dissertation, University of Amsterdam. The Hague: Holland Academic Graphics.

BoERsma, PAUL and DiANA APOUSSIDOU. 2004. In B.Schmeiser, V. Chand, A. Kelleher and A. Rodriguez (eds.) 'Comparing different Optimality-theoretic learning algorithms for Latin stress. Proceedings of WCCFL23 pp.29-42. Somerville, MA: Cascadilla Press.

Boersma, Paul and Bruce Hayes. 2001. Empirical Tests of the Gradual Learning Algorithm. Linguistic Inquiry vol. 32: 45-86. 
Boersma, PAUl \& DaVid WeEninK. 2007. Praat: doing phonetics by computer (Version 4.5.18) [Computer program].

BooiJ, GeERT. 1995. The Phonology of Dutch. Oxford: Clarendon Press.

Coetzee, Andries AND Joe PATER (to appear). Weighted Constraints and Gradient Restrictions on Place Co-Occurrence in Muna and Arabic. To appear in Natural Language and Linguistic Theory.

Côté, MARIE-HÉlÈne. Consonant cluster phonotactics: A perception-based approach. MIT Linguistics Dissertations. Cambridge: MIT Working Papers in Linguistics, 367 pp.

Curtin, SuZAnne. 2002. Representational Richness in Phonological Development. Ph.D. Dissertation, University of Southern California.

Curtin, Suzanne and Kie Zuraw. 2001. Explaining Constraint Demotion in a Developing System. In B. Skarabela, S. Fish and A. H-J. Do, (eds.), Proceedings of the 26th Annual Boston University Conference on Language Development, Somerville MA, Cascadilla.

DAVIS, STUART. 2003. 'Capitalistic vs. militaristic: the paradigm uniformity effect reconsidered. In L. Downing, T.A. Hall, and R. Raffelsiefen (eds.) Paradigms in Phonological Theory. Oxford: Oxford University Press, 107-121.

Demuth, Katherine. 1996. Stages in the acquisition of prosodic structure. In E. Clark (ed.), Proceedings of the 27th Child Language Research Forum. Stanford University: CSLI, 39-48.

Dresher, B. Elan and JonAthan Kaye. 1990. A Computational Learning Model for Metrical Phonology. Cognition 34.2: 137-195.

Dresher, B. Elan. 1999. Charting the Learning Path: Cues to Parameter Setting. Linguistic Inquiry 30.2: 27-67.

FIKKERT, PAulA. 1994. On the Acquisition of Prosodic Structure. Ph.D. dissertation, University of Leiden.

Echols, Catharine H. and Elissa Newport. 1992. The role of stress and position in determining first words. Language Acquisition 2:189-220.

FIKKeRT, PAUla. 1994. On the acquisition of prosodic structure. Ph.D. Dissertation, HIL dissertations 6, Leiden University. The Hague: Holland Academic Graphics.

FLEMMING, EDWARD. (2001). Scalar and categorical phenomena in a unified model of phonetics and phonology. Phonology, 18(1):7-44.

GERKEN, LOU ANN. 1996. 'Prosodic structure in young children's language production.' Language, 72, 683-712.

GIBSON, EDWARD and KENNETH WEXLER. 1994. Triggers. Linguistic Inquiry 25.3: 407-454.

GnANAdesikan, Amalia. 1995/2004. Markedness and Faithfulness Constraints in Child Phonology. In R. Kager, J. Pater \& W. Zonneveld (eds.), Fixing Priorities: Constraints in Phonological Acquisition. Cambridge, UK: Cambridge University Press.

GoAd, Heather and Yvan Rose. 2004. Input Elaboration, Head Faithfulness and Evidence for Representation in the Acquisition of Left-edge Clusters in West Germanic. In R. Kager, J. Pater \& W. Zonneveld (eds.), Fixing Priorities: Constraints in Phonological Acquisition. Cambridge, UK: Cambridge University Press.

Goldwater, SHARON and MARK JOHnSON. 2003. Learning OT Constraint Rankings Using a Maximum Entropy Model. Proceedings of the Workshop on Variation within Optimality Theory, Stockholm University. 
GousKova, MARIA. 2003. Deriving Economy: Syncope in Optimality Theory. Ph.D dissertation, University of Massachusetts Amherst. Amherst, MA: GLSA Publication.

HAYES, BRUCE. 2004. Phonological Acquisition in Optimality Theory: the early stages. In R. Kager, J. Pater \& W. Zonneveld (eds.), Fixing Priorities: Constraints in Phonological Acquisition. Cambridge, UK: Cambridge University Press.

HAYES, BRUCE AND ZsuZSA C. LONDE. 2006. 'Stochastic Phonological Knowledge: the case of Hungarian Vowel Harmony. Phonology 23:59-104.

Ito, JunKo and ARMin MeSTER. 1999. "The structure of the Phonological Lexicon". In N.Tsujimura, (ed.), The Handbook of Japanese Linguistics. Oxford: Blackwell: 62-100.

JAEGER, Gerhard. 2007. Maximum Entropy Models and Stochastic Optimality Theory. To appear in Jane Grimshaw, Joan Maling, Chris Manning, Jane Simpson, and Annie Zaenen (eds.), Architectures, Rules, and Preferences: A Festschrift for Joan Bresnan, CSLI Publications, Stanford.

JAROSZ, GAJA. 2006. Rich Lexicons and Restrictive Grammars - Maximum Likelihood Learning in Optimality Theory. Ph.D. Dissertation, Johns Hopkins University, Baltimore MD.

Jensen, John. 1993. English phonology. John Benjamins Publishing Company.

Jesney, Karen. 2006. Emergent OO-Faith Stages in a Weighted Constraint System. Ms., University of Massachusetts Amherst.

JESNEY, KAREN. 2007. The locus of variation in weighted constraint grammars. Poster presented at the Workshop on Variation, Gradience and Frequency in Phonology. Stanford, CA: Stanford University.

JeSNey, KAREN and ANNE-Michelle TeSSIER. 2007. Re-evaluating learning biases in Harmonig Grammar. In M. Becker (ed.) University of Massachusetts Occasional Papers 36: Papers in Theoretical and Computational Phonology. Amherst, MA: GLSA.

JESNEY, KAREN and ANNE-MiCHELle TESSIER. (2008). Gradual learning and faithfulness: consequences of ranked vs. weighted constraints. To appear in the proceedings of the 38th Meeting of the North East Linguistics Society (NELS 38).

Jun, Jongho. 1995. Perceptual and Articulatory Factors in Place Assimilation: An Optimality Theoretic Approach. Ph.D. dissertation, UCLA. Los Angeles, CA: UCLA Occasional Papers in Linguistics 16.

Kehoe, Margaret. 2000. Truncation Without Shape Constraints: The Latter Stages of Prosodic Acquisition. Language Acquisition 8(1): 23-67.

Kehoe, Margaret and Carol Stoel-Gammon. 1997. Truncation patterns in English-speaking children's word productions. Journal of Speech, Language, and Hearing Research 40: 526541.

Kehoe, Margaret and Geraldine Hilaire-Debove. 2004. The Structure of Branching Onsets and Rising Diphthongs: Evidence from the Acquisition of French. In Alejna Brugos, Linnea Micciulla, and Christine E. Smith (eds.), Proceedings of BUCLD 28. Somerville, MA: Cascadilla Press. 282-293.

KELLER, FRANK. 2006. Linear optimality theory as a model of gradience in grammar. In Gisbert Fanselow, Caroline Féry, Ralph Vogel, and Matthias Schlesewsky (eds.) Gradience in grammar: Generative perspectives, Oxford: Oxford University Press.

LEgendre, GÉRAldine, Yoshiro Miyata, and PAUl SMOlensky. 1990a. Harmonic Grammar a formal multi-level connectionist theory of linguistic wellformedness: An application. In 
Proceedings of the twelfth annual conference of the Cognitive Science Society, 884-891. Cambridge, MA: Lawrence Erlbaum.

Legendre, GÉRAldine, Yoshiro Miyata, and Paul SMOlensky. 1990b. Harmonic Grammar a formal multi-level connectionist theory of linguistic wellformedness: Theoretical foundations. In Proceedings of the twelfth annual conference of the Cognitive Science Society, 388-395. Cambridge, MA: Lawrence Erlbaum.

Legendre, GÉraldine, Antonella Sorace, and Paul Smolensky. 2006. The Optimality Theory-Harmonic Grammar connection. In P. Smolensky and G. Legendre (eds.) The harmonic mind: From neural computation to Optimality-Theoretic grammar, volume I: cognitive architecture. Cambridge, MA: MIT Press. pp. 903-966.

Levelt, Claartje. C. and Rubin Van De ViJVer. 2004. Syllable types in cross-linguistic and developmental grammars. In R. Kager, W. Zonneveld, J. Pater, (eds)., Fixing Priorities: Constraints in Phonological Acquisition. Cambridge, UK: Cambridge University Press.

LOMBARDI, LINDA. 1999. "Positional faithfulness and voicing assimilation in Optimality Theory," Natural Language and Linguistic Theory 17, 1999.

MACKEN, M. AND C. FERGUSON. 1983. Cognitive aspects of phonological development: Model, evidence and issues. In K. Nelson (ed.) Children's Language. vol 3. Hillsdale, NJ: Erlbaum.

MCCARTHY, JOHN J. 1998. Morpheme structure constraints and paradigm occultation. In M. Catherine Gruber, Derrick Higgins, Kenneth Olson, and Tamra Wysocki (eds.), Proceedings of the Chicago Linguistic Society 5, Vol. II: The Panels. Chicago: CLS.

MCCARTHY, JOHN J. 2003. 'OT constraints are categorical.' Phonology 20, 75-138.

MCCARTHY, John J. and Alan PRINCE. 1995. 'Faithfulness and Reduplicative Identity.' In J. Beckman, S. Urbanczyk and L. Walsh-Dickey (eds.). University of Massachusetts Occasional Papers in Linguistics 18: Papers in Optimality Theory. Amherst: GLSA. pp. 249-384

Menn, Lise. 1976. Pattern, control, and contrast in beginning speech: A case study in the development of word form and word function. Ph.D. dissertation, University of Illinois, Urbana.

MENN, LiSE. 1983. 'Development of articulatory, phonetic, and phonological categories. In B. Butterworth (ed.) Language production. New York: Academic Press.

PAter. Joe (1997). 'Minimal Violation and Phonological Development'. Language Acquisition 6(3): 201-253.

PATER, JOE (to appear). Gradual learning and convergence. Linguistic Inquiry.

PAter, Joe, Karen Jesney and Anne-Michelle Tessier (2007). Phonological Acquisition as Weighted Constraint Interaction. In Alyona Beliokova, Luisa Meroni, and Mari Umeda (eds.) Proceedings of the Conference on Generative Approaches to Language Acquisition - North America (GALANA 2), Somerville, MA: Cascadilla Proceedings Project.

Pater, Joe, Rajesh Bhatt And Christopher Potts 2007. Linguistic Optimization. Ms., UMass Amherst. [ROA 872-1006]

Christopher Potts, Joe Pater, Rajesh Bhatt and Michael Becker. 2008. Harmonic grammar with linear programming: From linear systems to linguistic typology. Ms., UMass Amherst. [ROA 984-0708]

PEARL, LisA. 2007. Necessary Bias in Natural Language Learning, Doctoral Dissertation, University of Maryland. 
PEARL, LISA. 2008. 'Putting the Emphasis on Unambiguous: The Feasibility of Data Filtering for Learning English Metrical Phonology.' In Chan, H., H. Jacob, and E. Kapia (eds.) BUCLD 32: Proceedings of the 32nd annual Boston University Conference on Child Language Development, , Somerville, MA: Cascadilla Press, 390-401.

Potts, Christopher, Michael Becker, Rajesh Bhatt \& Joe Pater. 2007. HaLP: Harmonic grammar with linear programming, version 2. Software available online at http://web.linguist.umass.edu/ halp/.

PRINCE, ALAN. 1983. Relating to the grid. Linguistic Inquiry 14.1, 19-100.

PRINCE, AlAn. 1997. 'Paninian relations'. Invited talk, Department of Linguistics, University of Massachusetts Amherst.

Prince, Alan. 2002a. Arguing optimality. In Andries Coetzee, Angela Carpenter, and Paul de Lacy (eds.) Papers in Optimality Theory II. Amherst, MA: GLSA. 269-304.

Prince, Alan. 2002b. Entailed ranking arguments. Ms., Rutgers University, New Brunswick, NJ. [ROA 500-0202.]

Prince, Alan and PAUl SMOLENSKy. 1993/2004. Optimality Theory: Constraint interaction in generative grammar. RuCCS Technical Report 2, Rutgers University, Piscateway, NJ: Rutgers University Center for Cognitive Science. [Revised version published by Blackwell.]

Prince, Alan and Bruce TeSAR. 2004. Learning Phonotactic Distributions. In R. Kager, W. Zonneveld, J. Pater, (eds)., Fixing Priorities: Constraints in Phonological Acquisition. Cambridge, UK: Cambridge University Press.

Pulleyblank, Douglas and William J. Turkel. 1998. The logical problem of language acquisition in optimality theory. In P. Barbosa, D. Fox, P. Hagstrom, M. McGinnis \& D. Pesetsky (eds.), Is the best good enough? Optimality and competition in syntax. Cambridge, MA: MIT Press, 399-420.

REVITHIADOU, ANTHI AND MARINA TZAKOSTA. 2004. Alternative grammars in acquisition: markedness- vs. faithfulness-oriented learning. Proceedings of BUCLD28, online supplement. [http://128.197.86.186/posters/revithiadou-BUCLD2003.pdf]

RoARK, BRIAN and KATHERINE DEMUTH. 2000. Prosodic Constraints and the Learner's Environment: a Corpus Study. In S. C. Howell, S. A. Fish, and T. Keith-Lucas (eds.), Proceedings of BUCLD 24. Somerville, MA: Cascadilla Press. pp. 597-608.

Rose, Yvan. 2000. Headedness and Prosodic Licensing in the L1 Acquisition of Phonology. Ph.D. dissertation, McGill University.

Smith, NeIL V. 1973. The acquisition of phonology: A case study. New York: Cambridge University Press.

SMith, JenNifER L. 2000. Positional faithfulness and learnability in Optimality Theory. In Rebecca Daly and A. Rehl (eds.), Proceedings of ESCOL99, Ithaca, CLC Publications.

SMith, JENNIFER L. 2001. 'Lexical Category and Phonological Contrast'. In R. Kirchner, J. Pater and W. Wikely (eds.) PETL6: Proceedings of the Workshop on the Lexicon in Phonetics and Phonology. Edmonton: University of Alberta. 61-72.

Smith, Jennifer L. 2002. Phonological Augmentation in Prominent Positions. PhD dissertation, University of Massachusetts, Amherst.

SMOLENSKY, PAUL. 1996. On the comprehension/production dilemma in child language. Linguistic Inquiry 27: 720-731. 
STERIADE, DONCA. 1999. Alternatives to the syllabic interpretation of consonantal phonotactics. In O.Fujimura B.Joseph and B.Palek (eds.) Proceedings of the 1998 Linguistics and Phonetics Conference, The Karolinum Press, 205-242

Stemberger, Joseph, Barbara Bernhardt and C.E. Johnson. 2001. "Regressions" ("u"shaped learning) in the acquisition of prosodic structure. ROA-471.

Stites, Jessica, Katherine Demuth and Cecilia KirK. 2004. Markedness versus frequency effects in coda acquisition. In Alejna Brugos, Linnea Micciulla, \& Christine E. Smith (eds.), Proceedings of BUCLD 28. Somerville, MA: Cascadilla Press. 565-576.

TESAR, BRUCE. 1998. 'An iterative strategy for language learning. Lingua 84: pp 131-155

TESAR, BRUCE. 2007. 'A Comparison of Lexicographic and Linear Numeric Optimization Using Violation Difference Ratios'. Ms. Rutgers University.

Tesar, Bruce and Paul SMOlensky. 1996. Learnability in Optimality Theory (short version). Technical Report JHU-CogSci-96-2, Cognitive Science Department, The Johns Hopkins University.

Tesar, Bruce and Paul Smolensky. 1998. Learnability in Optimality Theory. Linguistic Inquiry 29(2): 229-262.

TeSAR, BRUCE and PAUl SMOlEnsky. 2000. Learnability in Optimality Theory. Cambridge, MA: MIT Press.

Tessier, AnNe-Michelle. 2006. Stages of Phonological Acquisition and Error-Selective Learning. In Donald Baumer, David Montero, and Michael Scanlon (eds.) Proceedings of WCCFL25. Somerville, MA: Cascadilla Press. pp. 408-416.

Tessier, AnNe-Michelle. 2007. Biases and Stages in Phonological Acquisition. Ph.D. dissertation, University of Massachusetts Amherst.

Velleman, Shelley And Marilyn Vihman. 2003. 'The Optimal Initial State'. Ms., UMass Amherst and University of Wales at Bangor.

Zoll, Cheryl. 1998. Positional Asymmetries and Licensing. Ms., MIT. Available at http://roa.rutgers.edu/files/282-0998/roa-282-zoll-4.pdf.

ZURAW, KIE. 2000. Patterned exceptions in phonology. Ph.D. dissertation, UCLA. 